Article

\title{
Flexible Textile Strain Sensor Based on Copper-Coated Lyocell Type Cellulose Fabric
}

\author{
Waleri Root*(D), Tom Wright, Barnaby Caven $\mathbb{D}$, Thomas Bechtold and Tung Pham $\mathbb{D}$ \\ Research Institute for Textile Chemistry/Physics, University of Innsbruck, Hoechsterstrasse 73, \\ 6850 Dornbirn, Austria; tom.wright@uibk.ac.at (T.W.); barnaby.caven@uibk.ac.at (B.C.); \\ thomas.bechtold@uibk.ac.at (T.B.); tung.pham@uibk.ac.at (T.P.) \\ * Correspondence: waleri.root@uibk.ac.at
}

Received: 11 April 2019; Accepted: 29 April 2019; Published: 2 May 2019

check for updates

\begin{abstract}
Integration of sensors in textile garments requires the development of flexible conductive structures. In this work, cellulose-based woven lyocell fabrics were coated with copper during an electroless step, produced at $0.0284 \mathrm{M}$ copper sulfate pentahydrate, $0.079 \mathrm{M}$ potassium hydrogen L-tartrate, and $0.94 \mathrm{M}$ formaldehyde concentrations. High concentrations led to high homogeneous copper reaction rates and the heterogeneous copper deposition process was diffusion controlled. Thus, the rate of copper deposition did not increase on the cellulose surface. Conductivity of copper coatings was investigated by the resistance with a four probe technique during fabric deformation. In cyclic tensile tests, the resistance of coated fabric $\left(19 \times 1.5 \mathrm{~cm}^{2}\right)$ decreased from 13.2-3.7 $\Omega$ at $2.2 \%$ elongation. In flex tests, the resistance increased from 5.2-6.6 $\Omega$ after 5000 bending cycles. After repeated wetting and drying cycles, the resistance increased by $2.6 \times 10^{5}$. The resistance raised from $11-23 \Omega$ /square with increasing relative humidity from $20-80 \%$, which is likely due to hygroscopic expansion of fibers. This work improves the understanding of conductive copper coating on textiles and shows their applicability in flexible strain sensors.
\end{abstract}

Keywords: cellulose; electrical resistance; copper coating; electroless deposition; humidity sensor; strain sensor; lyocell fiber

\section{Introduction}

Flexible conductive materials have been extensively investigated according to their promising potential applications in energy storage devices, photodetectors, pressure sensors, and light emitting displays [1-3]. The current research shows the feasibility of fiber/fabric coating to induce electrical conductivity. Coating of metallic copper layers on woven cellulose lyocell (CLY) fabrics through electroless deposition is important to achieve a large area sensor network for wearable smart textiles.

Cellulose is an important textile substrate due to its biodegradable, biocompatible, eco-friendly, non-toxic, and renewable properties [4]. It is chosen according to its high mechanical modulus property, a high strength and an inflexible crystallinity [5]. Several approaches are reported in the literature about how conductive substrates are implemented in large area fabrics. Flexible large area sensors are used for pressure and temperature sensing consisting of an organic coating on plastic and rubber substrates [6,7]. Huang et al. used a $150 \mathrm{~cm}^{2}$ cloth on a woolen band consisting of steel yarns for energy storage [8]. Shur performed the deposition of CdS/CuS films on $8 \times 10$ inches foils, which were suitable for application in e-textiles [9]. Yang et al. manufactured a carbon cloth of $160 \mathrm{~cm}^{2}$, which is embedded with Nickel nanoparticles through a metal-mediated pitting method [10]. Matsuhisa et al. printed elastic textile conductors of $30 \times 20 \mathrm{~cm}^{2}$ size with silver nanoparticles which showed high conductivity after treatment [11]. 
Understanding the relationship between electrical conductivity and mechanical deformations of metal coated/electrical textiles remains under reported. Permanent stress and deformation of conductive textiles on textiles could lead to damages. It is essential to investigate the electrical resistance of conductive textiles during tensile strength and bending. Abry et al. investigated the damage in Carbon Fiber Reinforce Polymer (CFRP) by means of the electrical resistance [12]. Zhang et al. showed that knitted carbon fiber fabrics displayed greater changes in resistance under loading compared to stainless steel fabrics [13]. Lin et al. measured the electrical resistance during tensile loading on blended yarns consisting of polypropylene (PP) and polyethylene terephthalate (PET) coated with multi-walled carbon nanotubes (MWCNT) [14]. Perumalraj investigated the effect of the resistance on polyaniline (PANI) impregnated polyester/viscose, Bamboo, Bamboo/cotton and cotton fabrics [15]. Hansen et al. showed that Poly(3,4-ethylenedioxythiophene) and aliphatic polyurethane substrate retained conductive property during stretching and relaxation [16]. Kageyama et al. investigated a $\mathrm{BaTiO}_{3}$ impregnated carbon fabric, which indicated an electrical resistance during tensile tests [17]. The resistance of carbon nanotubes coated textile capacitor was studied by Yun et al. which investigated the behavior of resistance during mechanical strain in textile-based capacitors consisting of Carbon nanotubes coated fabrics [18]. Qu et al. reported the manufacture of extruded carbon fiber/polymethylmethacrylate composites, which increased their conductive property as the carbon fiber volume fraction for filaments of $1 \mathrm{~mm}$ and $3 \mathrm{~mm}$ diameter increased [19]. Won et al. explored copper nanowires with a high stretchable property for the application as stretchable electrodes [20]. Ali et al. detected the conductive property of cotton textiles impregnated with copper particles during an applied load as a function of elongation [21]. Nishio et al. used the four probe technique to measure the change of the electrical resistance of a woven fabric during cyclic elongation [22]. De Baere et al. measured the voltage in a carbon fabric composite by evaluating its electrical resistance [23]. Cui et al. investigated the electrical conductivity of cupro fabrics impregnated with silver nanowires during bending, shrinking and stretching [24]. Application in medicine, sports, energy storage [25] security and personal protection, military and fire departments are all suggested [26,27]. Conductive coatings on cotton textiles were used for sweat detection in a garment by measuring resistance [28] and for monitoring electrical signals of a plant during stimulation [29]. Zieba and Frydrysiak reported the response of resistance to elongation, strain or bending in a textile sensor for monitoring breathing [30]. Ehrmann et al. tested textile sensors in knitted fabrics for human breathing application by detecting the electrical resistance during elongation [31]. Li et al. investigated the increase of the length resistance of knitted conductive fabrics during extensile force [32]. In the review of Kongahage and Foroughi, conjugated double bond conductive polymers $(\mathrm{CP})$ were described as promising materials for actuators consisting of polypyrrole (PPy), polyaniline (PANI) and PEDOT:PSS substrates. Those CP actuators can be used to monitor bending and linear motion [33]. Atalay et al. constructed a knitted textile strain sensor made of conductive yarns for human body motion detection [34]. In a different work, Atalay et al. used silver (Ag) plated nylon yarns for measuring the tensile strength [35]. Body motion was monitored by a strain sensors during resistance change based on a stretchable and conductive plain woven polyester fabric [36].

In summary, the above-mentioned works showed a successful implementation of conductive materials as metals (e.g., $\mathrm{Cu}, \mathrm{Ag}$ ), carbon substrates, conductive polymers (e.g., PET, PANI) to introduce an electric property in non-conductive substrates (e.g., PP, polyester, Bamboo, cotton). Using silver as conducive material in non-conductive substrates can be explained due to its high electrical conductivity of $6.3 \times 10^{7} \mathrm{Sm}^{-1}$ compared to $5.9 \times 10^{7} \mathrm{Sm}^{-1}$ of copper and $2 \times 10^{5} \mathrm{Sm}^{-1}$ carbon (graphite) substrates. Despite the lower cost of copper $(\$ 6.7 / \mathrm{kg})$ compared to silver $(\$ 510 / \mathrm{kg})$, immediate oxide layer formation on the copper surface makes its application difficult [25]. The implementation of conductive materials in knitted fabrics and woven fabrics can be used in electronic components in textiles. An advantage of knitted fabrics is their good stretch ability, softness and durability, which makes their applications in strain/pressure sensors important. Woven fabrics were reported to be effective for the monitoring of the bending motion [26]. In the work of Ding et al., polyurethane (PU) nonwoven substrates were manufactured by electrospinning and were subsequently dip coated with conductive 
poly(3,4-ethylenedioxythiophene):poly(styrenesulfonate) (PEDOT:PSS) polymers. The PEDOT:PSS/PU substrates indicated a sheet resistance of $35-240 \Omega / \mathrm{sq}$, withstand a strain of $200 \%$ and showed a constant resistance after 10 stretch release cycles [37]. Mahmood et al., showed the manufacture of conductive graphene oxide glass fiber substrates, which impart an electrical resistivity of $10^{1} \Omega \mathrm{m}$ after electrophoretical deposition [38]. In the review, Ding et al. reported on the conductive sponges as pressure sensors like neat conductive sponges (e.g., impregnated with $\mathrm{Cu}$ nanowires, CNT), composite conductive sponges (e.g., composed of polyimide (PU), polyacrylonitrile (PAN)), conductive sponges impregnated with elastomers (e.g., silicone, polydimethylsiloxane (PDMS)) and like conductive material coated sponges (e.g., coated with carbon, Ag). The conductive sponges can be used for the human motion detection [39]. Baima et al. investigated fluoropolymer wrapped conductive threads in an electrical touch sensor assembly by using the triboelectric method known as the change of the surface potential resulted from the skin contact [40]. Ebrahimi and Gashti used PPy materials as electrical substrates in clay Ag-polypyrrole nanocomposites, which showed an enhanced electromagnetic shielding and conductive properties compared to untreated PPy materials after the photo reduction technique [41]. The use as wearable electronics to monitor different parameters from the environment such as temperature, pressure, moisture is clear.

Monitoring conductivity of electrical textiles through the resistance in a wet environment mimics the exposure of fabrics to rain and different humidity's. Wet and dry treatments of textiles might lead to stiffness or reactivity changes [42,43]. Kramar et al. measured the electrical resistance of cotton and viscose fabrics impregnated with $\mathrm{Ag}^{+}, \mathrm{Zn}^{2+}$, and $\mathrm{Cu}^{2+}$ ions at different relative humidity conditions [44], apart from the change in resistance due to the ion treatment the resistance also decreased with increasing humidity. Shim et al. used carbon nanotubes coated cotton threads for humidity sensing and for mechanical/chemical durability tests [45]. The advantage of using copper as conductive substrate is its high conductivity/cost ratio in comparison to silver or nickel [25]. In previous work, copper layers were formed by electroless deposition on small woven CLY fabrics inducing conductivity [46]. To the authors best knowledge, there are few treatise reporting on electroless copper deposition (ECD) on a large (or easily scalable) area, i.e., $21 \times 29 \mathrm{~cm}^{2}$ woven CLY fabric. Specifically, none dealing with the investigation of the influence of cyclic tensile tests, flex tests, extended water treatment for $18 \mathrm{~h}$ and different relative humidity on resistance. The aim of this work was to coat a $21 \times 29 \mathrm{~cm}^{2}$ CLY textile surface with a copper layer during electroless deposition from aqueous solution and investigate its resistance as a function of fabric deformation. It included an optimization of chemical concentrations of $\mathrm{CuSO}_{4}$, formaldehyde and potassium hydrogen tartrate to achieve a strong adhesive and continuous copper layer.

\section{Experimental}

Samples cut from $21 \times 29 \mathrm{~cm}^{2}$ copper-coated CLY fabrics were used for investigation of resistance change during extended water treatment times, different relative humidity, flex and cyclic tensile tests. The four probe technique was used to monitor the resistance during different relative humidity (RH), during tensile testing and after flex tests. For humidity tests, a climate chamber was used at $25^{\circ} \mathrm{C}$ for $6 \mathrm{~h}$.

\subsection{Materials}

The chemicals were used as received. Potassium hydrogen L-tartrate $\left(\mathrm{C}_{4} \mathrm{H}_{5} \mathrm{KO}_{6} 99\right.$ wt \%) was purchased form Fulka (Buchs, Switzerland). Tin(II) chloride $\times 2$ hydrate $\left(\mathrm{SnCl}_{2} \times 2 \mathrm{H}_{2} \mathrm{O}\right)$ and formaldehyde $\left(\mathrm{H}_{2} \mathrm{CO} 36.5 \mathrm{wt} \%\right)$ were received from Riedel-de-Haen (Seelze, Germany). copper sulphate pentahydrate $\left(\mathrm{CuSO}_{4} \times 5 \mathrm{H}_{2} \mathrm{O} 99.5 \mathrm{wt} \%\right)$, ethanol $\left(\mathrm{C}_{2} \mathrm{H}_{6} \mathrm{O}>99.8 \%\right.$ with ca. $1 \%$ Methyl Ethyl Ketone) and ammonia $\left(\mathrm{NH}_{3} 25\right.$ wt \%) were purchased from Carl $\mathrm{ROTH} \mathrm{GmbH}+\mathrm{Co}$. KG (Karlsruhe, Germany). Sodium carbonate $\left(\mathrm{Na}_{2} \mathrm{CO}_{3} 99\right.$ wt \%) was obtained form MERCK (Darmstadt, Germany). Silver nitrate $\left(\mathrm{AgNO}_{3} 99.9 \mathrm{wt} \%\right)$ was obtained from VWR PROLABO (Leuven, Belgium). Sodium hydroxide ( $\mathrm{NaOH} 50 \mathrm{wt} \%$ solution) was obtained form Deuring $\mathrm{GmbH} \& \mathrm{Co}$ KG (Hörbranz, Austria). The woven cellulose lyocell fabrics were kindly provided by Lenzing AG (Lenzing, Austria), which is a plain woven cellulose lyocell fabric $\left(143 \mathrm{~g} / \mathrm{m}^{2}\right.$ weight, fibers of 1.3 dtex linear density 
and $39 \mathrm{~mm}$ length, 40 warp and 31 fill threads per $\mathrm{cm}$ ). Filter papers (MN 615 1/4, $70 \mathrm{~g} / \mathrm{m}^{2}$, thickness $0.16 \mathrm{~mm}$, surface smooth, ash content $0.1 \%$, $\alpha$-Cellulose content $95 \%$, average retention capacity 4-12 $\mu \mathrm{m}$ ) of $110 \mathrm{~mm}$ diameter were obtained form MACHEREY-NAGEL GmbH/Düren/Germany.

\subsection{Electroless Copper Deposition on A4 Sized Fabrics}

The CLY fabrics $\left(A=21 \mathrm{~cm} \times 29.7 \mathrm{~cm}=623.7 \mathrm{~cm}^{2} \mathrm{~m}=5 \mathrm{~g}\right)$ were cleaned with $1.35 \mathrm{M} \mathrm{NaOH}$, $20 \mathrm{~mL} \mathrm{H}_{2} \mathrm{O}$ de-ionized (DI) solution for $10 \mathrm{~min}$. The surface of the CLY fabric was rinsed with $50 \mathrm{ml}$ $\mathrm{H}_{2} \mathrm{O}$ (DI) and dried at ambient conditions for $24 \mathrm{~h}$. The CLY fabric was dipped into 19.8 M EtOH (MEK) $100 \mathrm{~mL}$ and $0.029 \mathrm{M} \mathrm{SnCl}_{2} \times 2 \mathrm{H}_{2} \mathrm{O}$ solution for $1 \mathrm{~min}$. Afterwards, it was dried at ambient conditions for $1 \mathrm{~h}$. The CLY fabric was immersed into a $0.042 \mathrm{M} \mathrm{AgNO}_{3}, 100 \mathrm{~mL} \mathrm{H}_{2} \mathrm{O}$ (DI) and $2.64 \mathrm{~mL}$ $(1.43 \mathrm{M}) \mathrm{NH}_{3}$ solution for $1 \mathrm{~min}$ at $\mathrm{pH}$ 11.58. The CLY fabric was dried at ambient conditions for $24 \mathrm{~h}$. Different concentration of $\mathrm{C}_{4} \mathrm{H}_{5} \mathrm{KO}_{6}, \mathrm{CuSO}_{4} \times 5 \mathrm{H}_{2} \mathrm{O}, \mathrm{NaOH}, \mathrm{H}_{2} \mathrm{O}$ (DI) and $\mathrm{CH}_{2} \mathrm{O}$ were used. Constant contents of $0.019 \mathrm{M} \mathrm{Na}_{2} \mathrm{CO}_{3}$ and $\mathrm{H}_{2} \mathrm{O}$ (DI) were used in all experiments. As shown in Table 1, all experiments were performed for $3 \mathrm{~h}$ at $\mathrm{pH} 12.5$ and room temperature.

Table 1. Concentrations of chemicals used for electroless copper deposition.

\begin{tabular}{|c|c|c|c|c|}
\hline Sample Name & $\begin{array}{c}\mathrm{C}_{4} \mathrm{H}_{5} \mathrm{KO}_{6} \\
(\mathrm{M})\end{array}$ & $\begin{array}{c}\mathrm{NaOH}(50 \text { wt \%) } \\
\text { (M) }\end{array}$ & $\begin{array}{c}\mathrm{CuSO}_{4} \times 5 \mathrm{H}_{2} \mathrm{O} \\
(\mathrm{M})\end{array}$ & $\begin{array}{c}\mathrm{CH}_{2} \mathrm{O} \\
(\mathrm{M})\end{array}$ \\
\hline CU 1 & 0.079 & 0.5 & 0.0284 & 0.94 \\
\hline CU 2 & 0.158 & 1 & 0.0568 & 1.88 \\
\hline CU 3 & 0.236 & 1.5 & 0.0852 & 2.82 \\
\hline
\end{tabular}

\subsection{Flex Test}

The characteristics of fatigue due to cyclic bending of copper-coated CLY fabric strip were determined with an adapted method according to DIN 53 543:1979-02, DIN EN ISO 17707:2005-10 and EN ISO 20344:2004-10 standards. A Cu-coated strip with a size of $1.5 \mathrm{~cm} \times 20 \mathrm{~cm}$ was attached to the permanent bending machine and was exposed to a total number of 6000 bending cycle. All bending tests were performed at a bending rate of $180 \mathrm{cycle} / \mathrm{min}$. The top and bottom part of the copper-coated CLY fabric strip was fixed with two jaws. $10 \mathrm{~cm}$ length of the copper-coated fabric strip were suspended to permanent bending at bending apparat (Biegeprüfmaschine (BPM), Pirmasens, Germany). The angle of friction change from $111^{\circ}$ to $179^{\circ}$ during flex tests.

\subsection{Resistance During Cyclic Elongation}

The sheet resistance of copper-coated CLY fabrics was investigated during repetitive elongation in relation to the ASTM D 257-07 standard. The copper-coated CLY fabric strips had the size of $1.5 \times 19 \mathrm{~cm}^{2}$ and were placed between jaws with a rubber isolation layer at a grip to grip separation of $100 \mathrm{~mm}$. Metallic copper strips monitored the resistance of the copper-coated CLY fabrics. The fabric was elongated and relaxed during permanent elongation cycles (Zwick/Roell/Ulm/Germany (Z010 test Control II)). The preload was set to $5 \mathrm{~N}$ with $50 \mathrm{~mm} / \mathrm{min}$ speed and $60 \mathrm{sec}$ time. The standard force increased from $2.24 \mathrm{~N}, 10 \mathrm{~N}, 20 \mathrm{~N}$, until a maximum of $30 \mathrm{~N}$ and decreased back to $20 \mathrm{~N}, 10 \mathrm{~N}, 2.24 \mathrm{~N}$ at a speed of $100 \mathrm{~mm} / \mathrm{min}$. Measurements were taken at a constant current of $20 \mathrm{~mA}$ applied by the power supply and voltage was monitored with a multimeter during fabric deformation tests. The two inner strips recorded the voltage during each load for $30 \mathrm{~s}$ and the resistance $(R)$ was evaluated according to the equation below:

$$
R=(U \times w) /(I \times l)
$$

where $U$ is the measured voltage, $I$ the applied current, $w$ the width of the $\mathrm{Cu}$ fabric strip and $l$ the investigated distance between the electrodes. During extended water treatments, the resistance of copper layer on CLY fabrics was measured with a multimeter (FLUKE) in a $100 \mathrm{~mL} \mathrm{H}_{2} \mathrm{O}$ (DI) solution stirring at $750 \mathrm{rpm}$ for $18 \mathrm{~h}$. 


\subsection{Electrical Resistivity Tests in Fabrics}

The electrical resistivity of dry fabric was measured with METRISO/3000 resister tester (Wolfgang Warmbler/Eppingen/Germany) for silver seeded CLY fabrics relating to the DIN 54345 standard. The values were recorded after one minute at $505 \mathrm{~V}$ and the measurements were repeated for three times.

\subsection{Four Probe Technique Measurements}

The sheet resistance $\left(R_{s h}\right)$ was measured in a coaxial arrangement with a four point probe technique at a spacing of $1 \mathrm{~cm}$ between the electrodes. The resistance was evaluated according to the equation below:

$$
R_{s h}=4.532 \times(U / I)
$$

where $U$ is the measured voltage and $I$ the applied current. All measurements were related to the ASTM standard F1529-94.

\subsection{Copper and Silver Determined with AAS (Atomic Absorption Spectroscopy)}

$50 \mathrm{mg}$ of the copper-coated fabric was cut from a $5 \mathrm{~g}$ CLY fabric and was immersed into a (15 wt \%) nitric acid $\left(\mathrm{HNO}_{3}\right)$ solution $(30 \mathrm{~mL})$ at $80{ }^{\circ} \mathrm{C}$ for $2 \mathrm{~h}$. The extraction solution was filtered with a filter paper $(\mathrm{d}=110 \mathrm{~mm})$ for $5 \mathrm{~min}$. A $10 \mathrm{mg} / \mathrm{L}$ stock solution of $\mathrm{Ag}^{+}\left(0.46 \times 10^{-3} \mathrm{M} \mathrm{AgNO}_{3}\right)$ and $10 \mathrm{mg} / \mathrm{L}$ of $\mathrm{Cu}^{2+}\left(0.16 \times 10^{-3} \mathrm{M} \mathrm{CuSO}_{4} \times 5 \mathrm{H}_{2} \mathrm{O}\right)$ were used to prepare calibration solutions in the range of $0-2 \mathrm{mg} / \mathrm{L}$ for $\mathrm{Cu}^{2+}, 0-1.5 \mathrm{mg} / \mathrm{L}$ for $\mathrm{Ag}^{+}$. The flasks $(100 \mathrm{~mL})$ and tubes $(50 \mathrm{~mL})$ were rinsed with $(6 \mathrm{wt} \%) \mathrm{HNO}_{3}$ before AAS measurement. Silver $(\mathrm{Ag})$ and copper $(\mathrm{Cu})$ contents in CLY fabrics were determined with AAS (contrAA 300, Analytic, Jena Germany) in an air-acetylene flame with a $100 \mathrm{~mm}$ burner at a wavelength of $328.1 \mathrm{~nm}$ for $\mathrm{Ag}$ and of $324.8 \mathrm{~nm}$ for $\mathrm{Cu}$. Linear regression of the calibration standards and the sample absorbance were used for the metal content detection in CLY fabrics. The metallic content was obtained due to Equation (3) in CLY fabrics. The analysis was related to DIN 38404 Teil 18, EN ISO 17294-2 and DIN 38406 Teil 7.

$$
C u_{f}=\left(C u_{s} \times V\right) / W
$$

where $C u_{f}$ is a copper content in fabric $(\mathrm{mg} / \mathrm{g}), C u_{s}$ is a Cu content in dilute solution $(\mathrm{mg} / \mathrm{L}), W$ is the mass of the investigated fabric piece $(\mathrm{g})$ and $V$ is a volume of extraction solution $(\mathrm{mL})$.

\subsection{Topology Investigations}

The environmental scanning electron microscopy (ESEM) and energy-dispersive X-ray spectroscopy (EDX) were conducted with the JEOL JSM-7100F microscope, which was operated in the range of 10-20 keV. The copper-coated CLY samples were placed on an aluminium specimen with a conductive carbon layer on top without any coating. All machine operating are given specific parameters in the figures. The topology was investigated with a laser scanning microscope (VK-X100 series LSM 3D Profile Measurement from KEYENCE). The images were recorded with a $100 \times$ lens at a working distance of $4.7 \mathrm{~mm}$. The samples were not under tension and were placed on a paper sheet during measurements. The topology of copper-coated CLY samples was characterized with Laser Scanning Microscopy (VK-X100 series LSM 3D Profile Measurement, KEYENCE, Tokyo, Japan). All FTIR measurements were conducted with the ATR-FTIR device (Vector 22, Bruker, Karlsruhe, Germany).

\section{Results and Discussion}

\subsection{Electroless Copper Deposition on $21 \times 29 \mathrm{~cm}^{2}$ Cellulose Fabrics}

Table 2 shows a summary of results of CLY fabrics produces at different molar concentrations of $\mathrm{CuSO}_{4}, \mathrm{H}_{2} \mathrm{CO}$ and $\mathrm{C}_{4} \mathrm{H}_{5} \mathrm{KO}_{6}$ during the ECD. The silver content [Ag] on the cellulose substrate indicates a high resistance $(R)$ due to silver seeds, which are not connected to one another. The copper-coated fabrics 
(CU 1, CU 2, CU 3) indicated different copper contents [Cu], roughness along the line values $\left(S_{h}\right)$, sheet resistances $\left(R_{s h}\right)$ and sheet conductance values $\left(G_{s h}\right)$. The Cu1 sample showed the lowest sheet resistance, lowest copper content and the highest sheet conductance comparing to $\mathrm{Cu} 2$ and $\mathrm{Cu} 3$ samples.

Table 2. Summary of metallic content, moisture and conductivity in copper-coated cellulose lyocell (CLY) fabrics. Values defined as mean \pm standard deviation.

\begin{tabular}{cccccccc}
\hline $\begin{array}{c}\text { Sample } \\
\text { Name }\end{array}$ & $\begin{array}{c}{[\mathbf{A g}]} \\
\mathbf{m g} / \mathbf{g}\end{array}$ & $\begin{array}{c}\boldsymbol{R} \text { Ag Seed } \\
\text { Fabric }(\boldsymbol{\Omega})\end{array}$ & $\begin{array}{c}\text { Cu Content } \\
\mathbf{~} \mathbf{g} / \mathbf{g}\end{array}$ & $\begin{array}{c}\mathbf{S}_{\mathbf{h}} \\
\boldsymbol{\mu m}\end{array}$ & $\begin{array}{c}\mathbf{R}_{\mathbf{s h}} \\
\mathbf{\Omega s q}^{-\mathbf{1}}\end{array}$ & $\begin{array}{c}\mathbf{G}_{\mathbf{s h}} \\
\mathbf{\Omega}^{-\mathbf{1}}\end{array}$ & $\begin{array}{c}\eta \text { Efficiency } \\
\text { of the Process }\end{array}$ \\
\hline CU 1 & $6.5 \pm 0.5$ & $1.3 \times 10^{11}$ & $147 \pm 0.3$ & $2.75 \pm 0.7$ & $1.89 \pm 0.9$ & $0.66 \pm 1.1$ & 0.81 \\
CU 2 & $14 \pm 0.4$ & $1.3 \times 10^{11}$ & $234 \pm 1.7$ & $1.94 \pm 0.3$ & $5.24 \pm 1.9$ & $0.21 \pm 0.1$ & 0.65 \\
CU 3 & $42 \pm 1.0$ & $1.3 \times 10^{11}$ & $198 \pm 0.2$ & $1.54 \pm 0.3$ & $2.46 \pm 2.0$ & $0.62 \pm 0.4$ & 0.37 \\
\hline
\end{tabular}

In Table 2, sample CU 3 showed a coated and uncoated copper surface, although the amount of copper was high due to the high $\mathrm{Cu}$ concentrations in solution. The overall deposition rate $\left(\mathrm{dCu}^{0} / \mathrm{dt}\right)$ of the electroless copper deposition can be explained by Equation (4). The first term describes a heterogeneous copper deposition rate $\left(d C u^{0} / d t\right)_{h e t}$ on the textile surface $(A)$ and the second term shows a homogenous copper reaction rate $\left(d C u^{0} / d t\right)_{\text {hom }}$ in solution.

$$
\frac{d C u^{0}}{d t}=\left(\frac{d C u^{0}}{d t}\right)_{h e t}+\left(\frac{d C u^{0}}{d t}\right)_{h o m}
$$

The heterogeneous copper deposition rate depends on the $\left[\mathrm{OH}^{-}\right]$hydroxyl, $\left[\mathrm{Cu}^{2+}\right]$ ion, $[$ Tartrate $]$ complexing agent, $\left[\mathrm{CH}_{2} \mathrm{O}\right]$ formaldehyde concentrations and the textile surface $(A)$ as is shown in Equation (5).

$$
\left(\frac{d C u^{0}}{d t}\right)_{\text {het }}=k_{\text {het }} \times\left[\mathrm{OH}^{-}\right] \times\left[\mathrm{Cu}^{2+}\right] \times\left[\mathrm{CH}_{2} \mathrm{O}\right] \times A \times 1 /[\text { Tartrate }]
$$

The homogeneous copper reaction rate in solution does not depend on the textile surface $(A)$, which is shown in Equation (6).

$$
\left(\frac{d \mathrm{Cu} u^{0}}{d t}\right)_{h o m}=k_{\text {hom }} \times\left[\mathrm{OH}^{-}\right] \times\left[\mathrm{Cu}^{2+}\right] \times\left[\mathrm{CH}_{2} \mathrm{O}\right] \times 1 /[\text { Tartrate }]
$$

where $k_{\text {het }}$ and $k_{\text {hom }}$ are kinetic constants for heterogeneous and homogenous reactions.

At low $\mathrm{OH}^{-}$, Tartrate, $\mathrm{Cu}^{2+}$ and $\mathrm{CH}_{2} \mathrm{O}$ concentrations in solution, the overall copper deposition reaction rate is slow and occurs mainly on the textile surface as highlighted by the green arrow (Figure 1a). The heterogeneous copper deposition rate is large comparing to the homogenous copper reaction rate, which leads to a slow reaction in solution (red arrow).

(a)

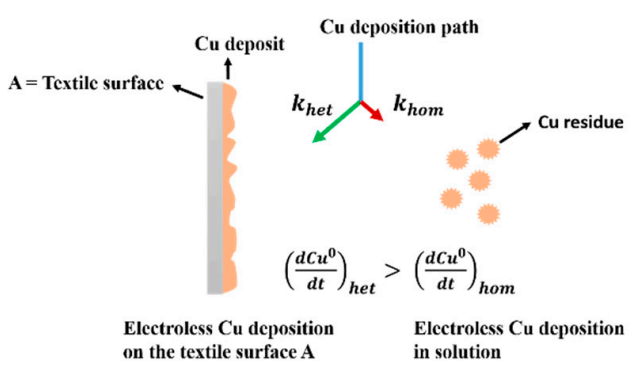

(b)

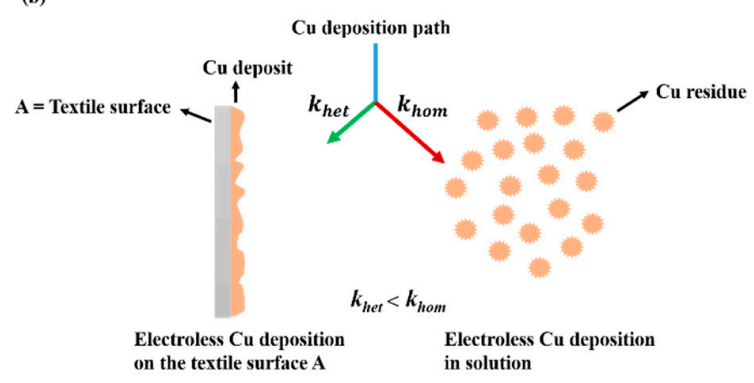

Figure 1. A schematic drawing of the electroless copper deposition during low (a) and high (b) $\mathrm{Cu}^{2+}$ concentrations in solution. 
At high $\mathrm{OH}^{-}, \mathrm{Cu}^{2+}$, Tartrate and $\mathrm{CH}_{2} \mathrm{O}$ concentrations in solution, the heterogeneous copper deposition rate on CLY surface $(A)$ competes with the homogeneous copper reaction rate in solution (Figure $1 \mathrm{~b}$ ). The diffusion of $\mathrm{Cu}^{2+}$ ions to the textile surface (a) limits the copper deposition rate. Thus, the formation of copper residue occurs in solution simultaneously to the copper deposition on the textile surface $(A)$ and the overall copper deposition rate is large.

An adaptation of the overall $\mathrm{Cu}^{0}$ deposition rate will be necessary if the $\mathrm{Cu}^{2+}$ concentration changes. Figure 2a,b depicts a theoretical and experimental work of the electroless $\mathrm{Cu}$ deposition.
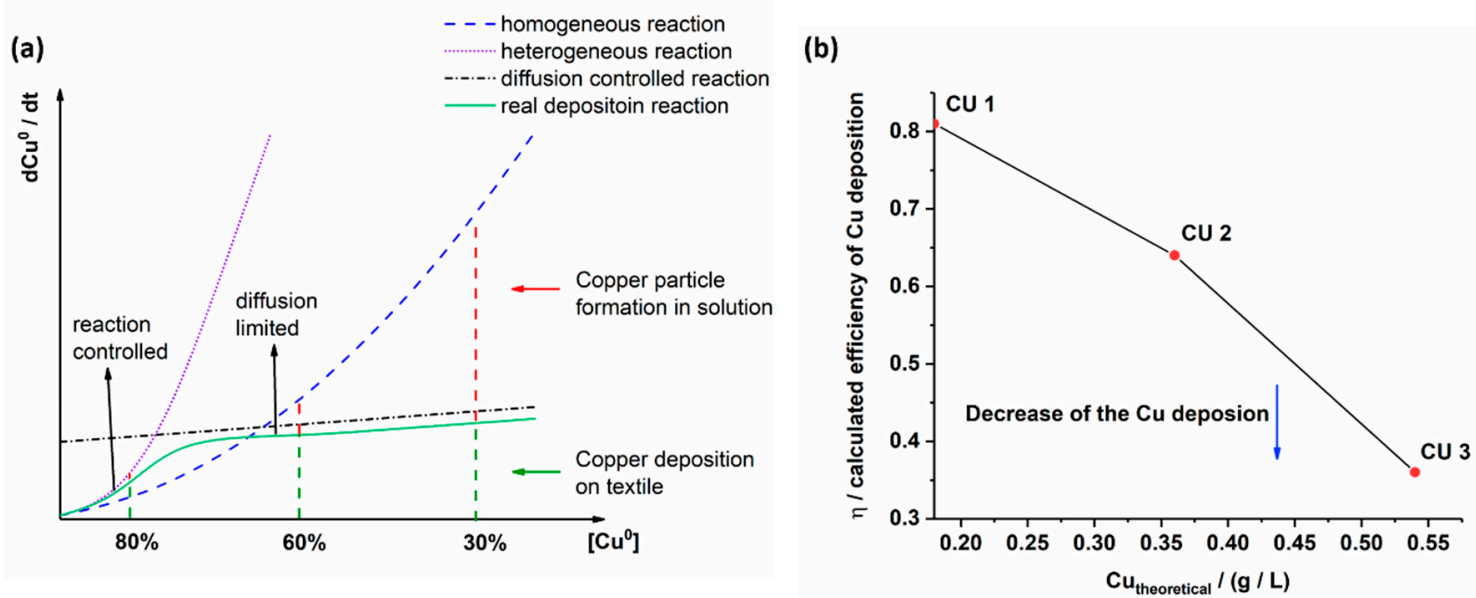

Figure 2. Theoretical (a) and experimental work (b) of the copper deposition on the textile surface.

At low chemical concentrations (Figure 2a, the reduction and deposition of metallic copper on the silver seeded textile surface depends on $\mathrm{Cu}^{2+}$ ion diffusion in solution (diffusion controlled reaction). The reduction of $\mathrm{Cu}^{2+}$ to $\mathrm{Cu}^{0}$ near the surface $(A)$ is fast (heterogeneous reaction) and for the copper layer formation $\mathrm{Cu}^{2+}$ ions diffuse from solution to the silver seed textile surface where reduction to $\mathrm{Cu}^{0}$ occurs. Thus, a copper layer grows continuously by contributing more $\mathrm{Cu}^{2+}$ ions from solution (real reaction), which explains the large amount of copper $(80 \%)$ detected on the silver seed textile surface. Side reaction as copper deposition on the beaker walls and the not reduced $\mathrm{Cu}^{2+}$ ions in solution are not pronounced. Increasing chemical concentrations $\left(\mathrm{Cu}^{2+}, \mathrm{C}_{4} \mathrm{H}_{5} \mathrm{KO}_{6}, \mathrm{CH}_{2} \mathrm{O}, \mathrm{OH}^{-}\right)$lead to pronounced reduction rate and copper particle formation in solution (homogeneous reaction). As a result, the amount of copper on the textile surface decreases $(60 \%)$. The formation of copper particles refers to the nucleation in solution, which compete with silver seeds on the textile for the $\mathrm{Cu}^{2+}$ ion consumption. At high chemical concentrations $\left(\mathrm{Cu}^{2+}\right)$, nucleation and growth of copper particles in solution dominate over the copper deposition on the textile surface. The heterogeneous deposition of copper at the textile surface enters into a diffusion controlled reaction, thus further increase in $\mathrm{Cu}^{0}$ formation does not occur (30\%). The $\mathrm{Cu}^{0}$ formation in the bulk solution however gain importance. The plots were made with regard to various simplifying assumptions such as a constant volume of $\mathrm{H}_{2} \mathrm{O}$ (DI), beaker shape and textile surface during the experiments. In Figure $2 b$ the calculated efficiency $\eta$ of the copper deposition is high at low $\mathrm{Cu}^{2+}$ concentrations (CU 1). It drops for $\mathrm{CU} 2$ and CU 3 samples at high $\mathrm{Cu}^{2+}$ concentrations. Based on the conditions in $\mathrm{CU} 1$ an enhancement of copper deposition on textiles can be worked out by adding small $\mathrm{OH}^{-}, \mathrm{Cu}^{2+}$ and $\mathrm{CH}_{2} \mathrm{O}$ concentrations to the solution over time. The theoretical work corresponds well to the experimental work of CU 1, CU 2 and CU 3 samples manufacture.

Apart from the copper coating deposition at the silver seeded CLY fabric, high $\mathrm{Cu}^{2+}$ concentrations $(0.0568 \mathrm{M}, 0.0852 \mathrm{M})$ enhanced the kinetic reaction for the copper residue formation in solution (Figure 3$)$. At high $\mathrm{Cu}^{2+}$, formaldehyde and $\mathrm{C}_{4} \mathrm{H}_{5} \mathrm{KO}_{6}$ concentrations, copper residue of $1 \mu \mathrm{m}$ formed in solution, which is shown in Figure $3 \mathrm{~b}$ for the CU 2 sample. According to EDX (Figure 3c), the copper residue shows peaks of higher relative intensity for copper with respect to the oxygen peak, which may indicate the formation of copper particles in solution. 

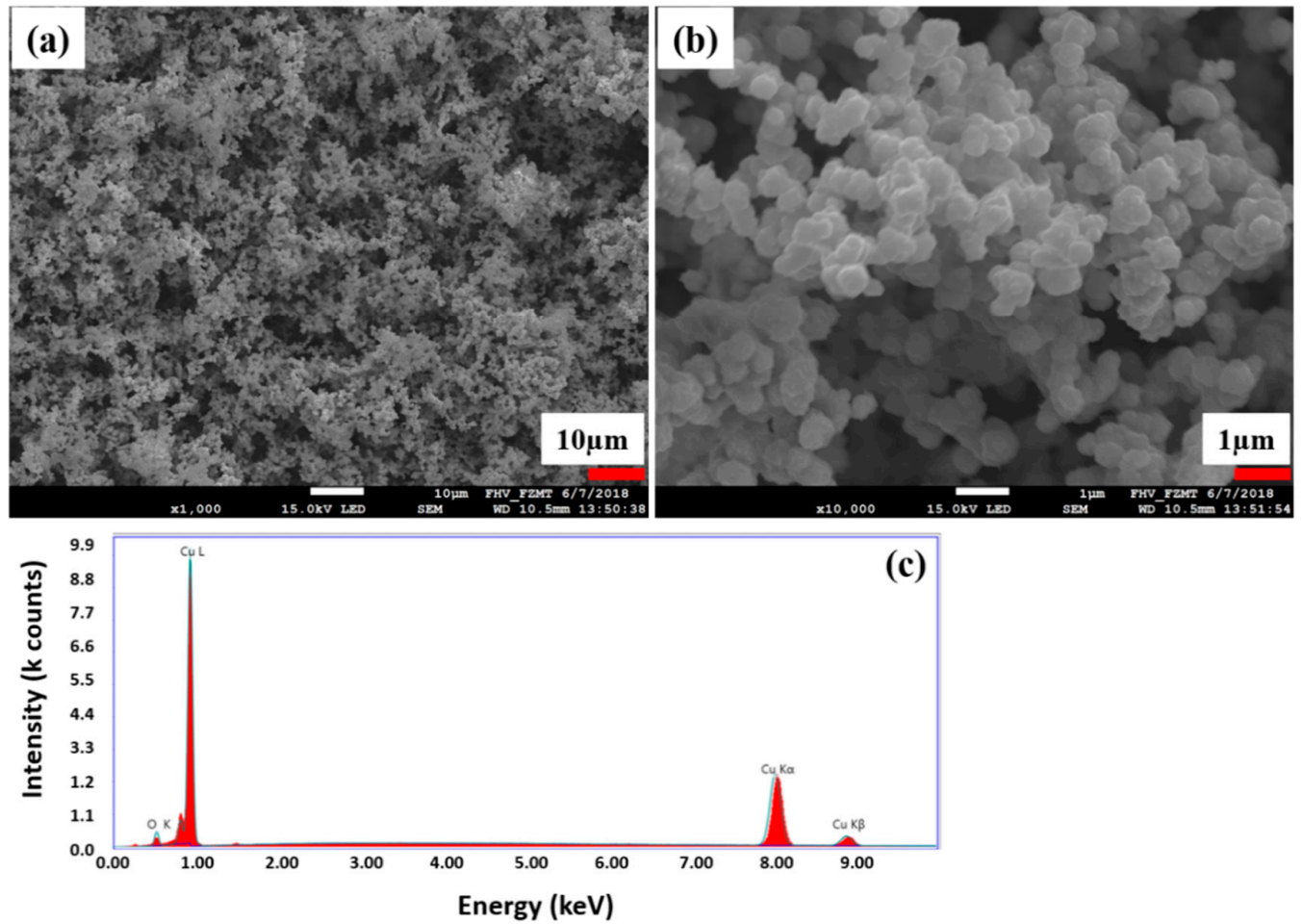

Figure 3. Fragile copper residue $(\mathbf{a}, \mathbf{b})$ formed during the electroless copper coating of fabric (CU 2) is investigated with EDX (c).

Due to the lowest sheet resistance and continuous copper layer, the Cu1 sample was chosen for further investigation in mechanical tests.

Figure 4a,b shows a random distribution of the silver seeds on CLY fabric, which build a catalytic surface for the electroless copper deposition. Relative intensity peaks of Ag and Sn are high when the EDX investigation is focused on a single silver seed (Figure 4c,d) comparing to the yarn surface. High relative intensity peaks of $\mathrm{C}$ (carbon), $\mathrm{O}$ (oxygen) species resulting from the cellulose substrate. $\mathrm{Sn}^{2+}$ reduced $\mathrm{Ag}^{+}$to $\mathrm{Ag}^{0}$ (metallic) from aqueous solution and formed a silver seed as catalytic surface on the CLY fabric. No continuous Ag layer was observed on the CLY surface.
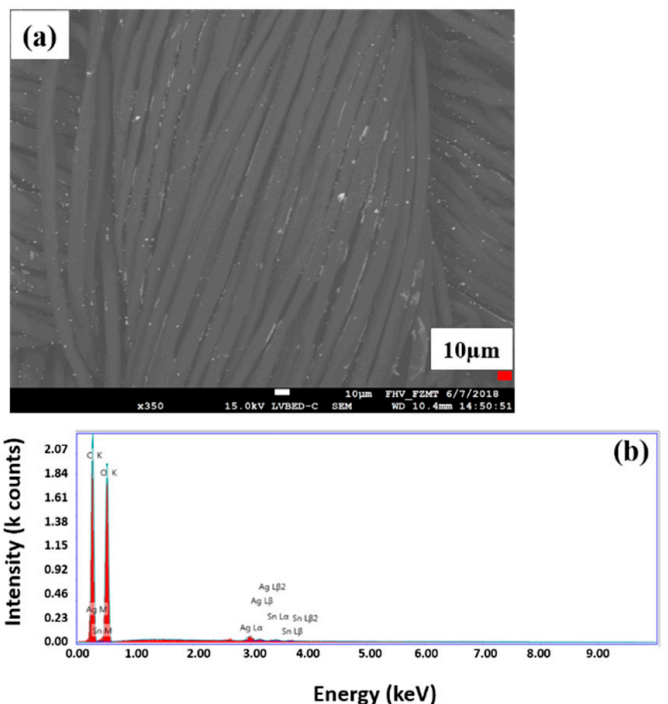
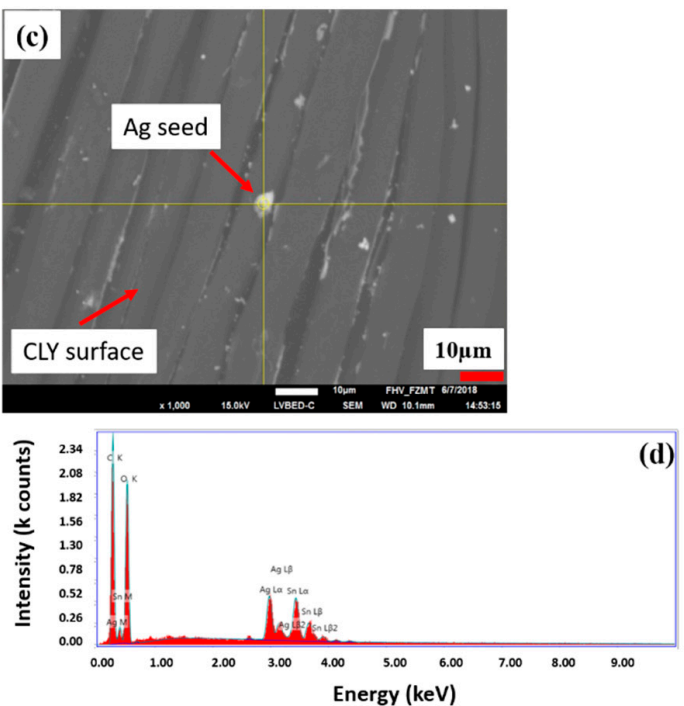

Figure 4. The surface of a silver seeded CLY (CU 1) sample is investigated with SEM (a) and EDX investigation (b). The magnification a silver seed (c) is shown, which is investigated with EDX (d). 
The silver content in Table 2 is too high to be related only to silver seed of $8 \mu \mathrm{m}$ size (Figure 3c) and Figure 4c shows silver seeds smaller than $8 \mu \mathrm{m}$. The silver seeds had different sizes and were randomly distributed on the CLY surface. In Table 2, the content of silver [Ag] is lower in comparison to the copper content. Thus, silver seeded CLY fabrics indicated a high resistance in G $\Omega$ (Giga Ohm) range, which drops to $1.89 \Omega \mathrm{sq}^{-1}$ and $5.24 \Omega \mathrm{sq}^{-1}$ after the ECD. The copper-coated CLY fabrics reveal a conductive property due to the copper coating.

\subsection{Topological Investigation of the Copper Coating}

Figure 5 indicates topological investigations of untreated (a), a silver seeded (b) and copper-coated CU 1 (c) samples.

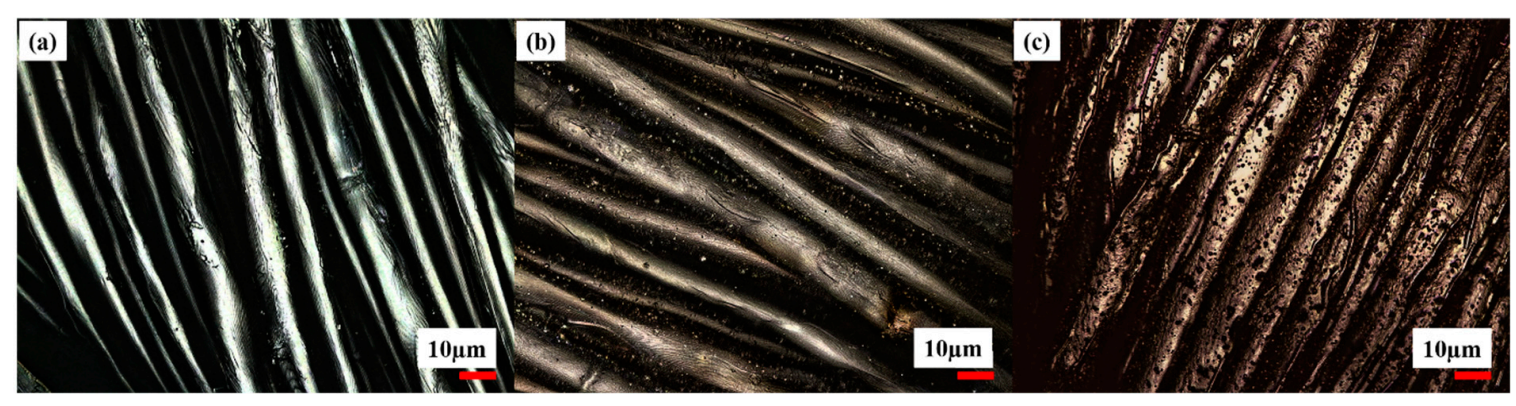

Figure 5. Topology investigation of uncoated (a), silver seeded (treated at $\left.0.042 \mathrm{M} \mathrm{AgNO}_{3}\right)(\mathbf{b}$ ), and copper layer coated (c) CLY CU 1 sample.

The topology investigations showed a gray image of untreated (Figure 5a), a bright yellow image after silver seeding (Figure 5b) and dark red copper-coated image of the CLY fabric (Figure 5c). For additional topological investigation, the copper-coated CLY CU 1 sample is investigated with SEM/EDX (Figure 6). Bright areas consists of a higher copper density in comparison to dark areas. Copper islands (bright areas) grow on a continuous copper layer (dark areas) as highlighted in Figure $6 \mathrm{a}, \mathrm{b}$. The surface might contain impurities like copper oxides, or organics due to EDX spectra (Figure 6d). Besides $\mathrm{Cu}, \mathrm{O}$ and $\mathrm{C}$ elements were detected, which were related to the CLY. 

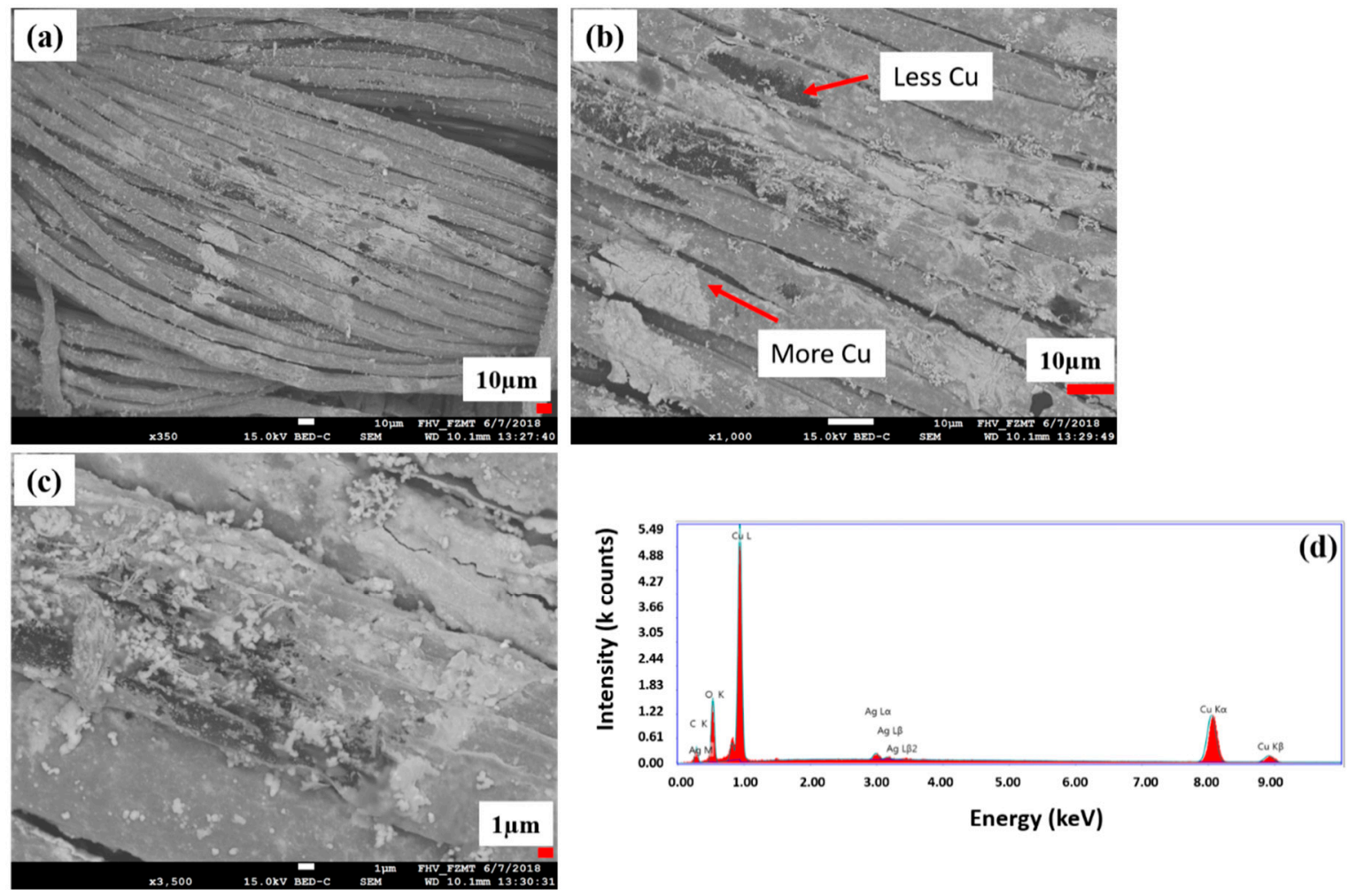

Figure 6. Topology of the copper-coated CLY (CU 1) fabric investigated with SEM (a-c) and EDX (d). High copper amount appears in bright color and low copper amount in dark color.

Figure $6 \mathrm{c}$ depicts copper islands smaller than $1 \mu \mathrm{m}$, which could be explained by a staggered layer growth during the ECD. Copper might grow in two directions as a copper island (bright color) by increasing its thickness and as a layer (dark color) covering the cellulose surface.

Table 3 is related to the EDX spectra in Figure $6 \mathrm{a}, \mathrm{d}$, which shows the elemental distribution of $\mathrm{Cu}$, $\mathrm{O}, \mathrm{C}$ and $\mathrm{Ag}$ from the copper-coated cellulose surface (CU 1). It indicates that the $\mathrm{Cu}$ element has the highest weight proportion of $81.36 \%$ compared to the O element of $9.46 \%$, C element of $7.4 \%$ and $\mathrm{Ag}$ element of $1.77 \%$ on the copper-coated cellulose sample.

Table 3. Summary of the elemental distribution from the copper-coated cellulose (CU 1) fabric.

\begin{tabular}{ccccc}
\hline Element & $\begin{array}{c}\text { Weight } \\
(\mathbf{\%})\end{array}$ & $\begin{array}{c}\text { Atom } \\
(\mathbf{\%})\end{array}$ & Net. Int. & $\begin{array}{c}\text { Error } \\
\mathbf{( \% )}\end{array}$ \\
\hline $\mathrm{C}(\mathrm{K})$ & 7.40 & 24.60 & 66.92 & 11.67 \\
$\mathrm{O}(\mathrm{K})$ & 9.46 & 23.62 & 303.38 & 8.55 \\
$\mathrm{Ag}(\mathrm{L})$ & 1.77 & 0.66 & 51.29 & 13.88 \\
$\mathrm{Cu}(\mathrm{K})$ & 81.36 & 51.12 & 632.75 & 3.85 \\
\hline
\end{tabular}

\subsection{Cross-Section and Copper-Coated Lyocell Yarn}

In Figure 7, a cross-section of the copper-coated CU 1 sample is investigated. According to the topological LSM and SEM investigations, the CU 1 sample shows less copper amount (bright color) in the interior side comparing to its outer surface (Figure 7a,c). 

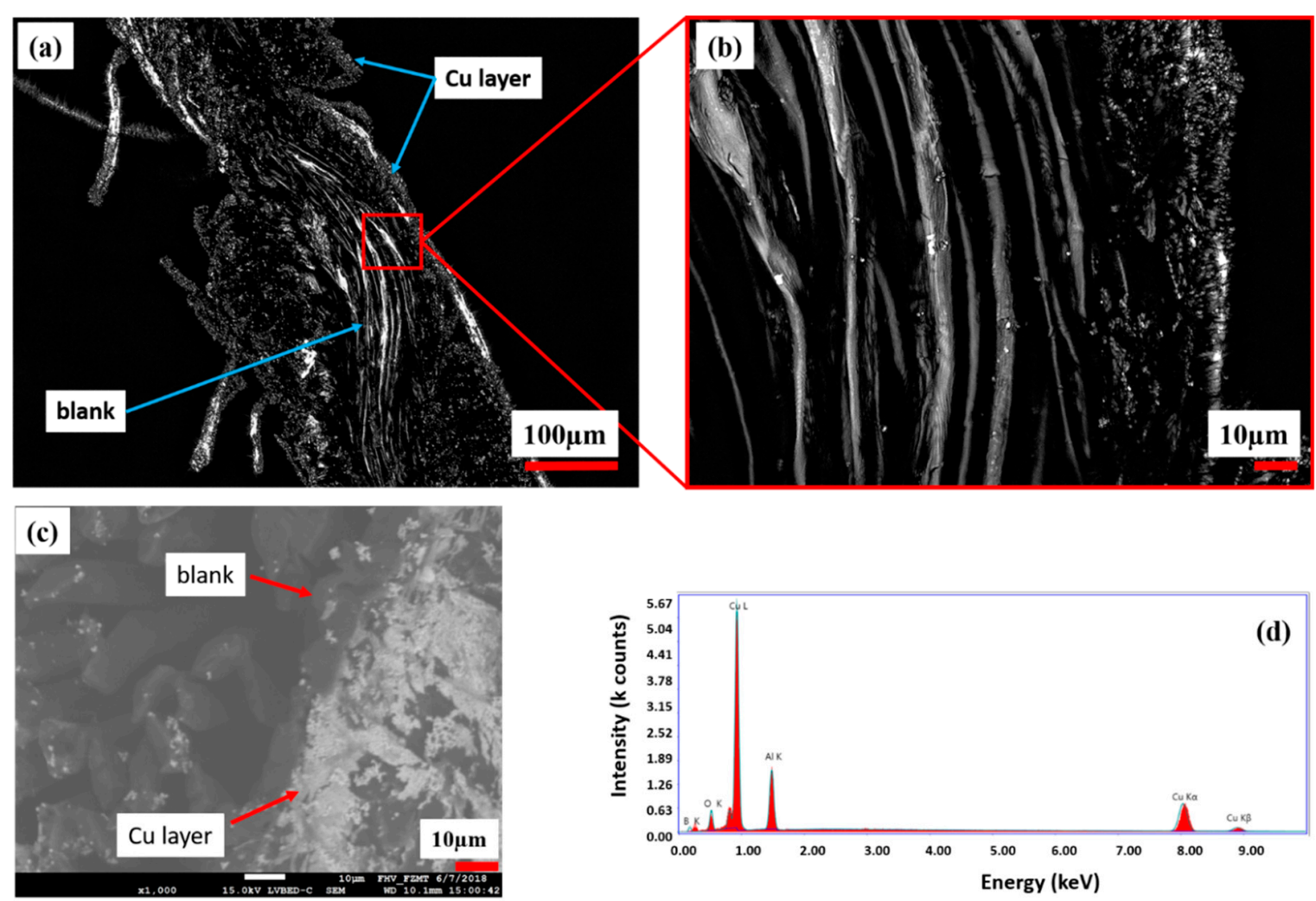

Figure 7. Cross section of the copper-coated CLY fabric (CU 1) and its magnification (a,b) captured with LSM. SEM/EDX investigation of the same cross section are shown in (c,d).

In Figure 7c, bright areas are related to the copper layer, which is formed on the outer surface of the $\mathrm{CU} 1$ cross section. Figure $7 \mathrm{~d}$ indicates high relative intensity $\mathrm{Cu}$ peaks comparing to $\mathrm{O}$ peaks, which are recorded from the cross section. The appearance of $\mathrm{Al}$ and $\mathrm{B}$ peaks resulted from the $\mathrm{Al}$ table as unwanted side effects and could not be excluded during measurement. There was no continuous copper layer observed in the interior side of the CLY cross section. The Cu deposition occurred on the silver seeded CLY fabric surface and stagnated in the interior side due the low accessibility of solution.

One single yarn was separated from the copper-coated CU 1 CLY fabric and its topology was characterized with SEM/EDX (Figure 8a). Figure 8b shows three copper areas on the CLY yarn appearing in bright color for the copper coating (area 1), in grey for an intermediate coating (area 2) and in dark for non-coated area 3. Each area was investigated separately with EDX, which revealed different copper amounts. Different copper coatings are related to the yarn directions in warp and weft on the CLY sample. 

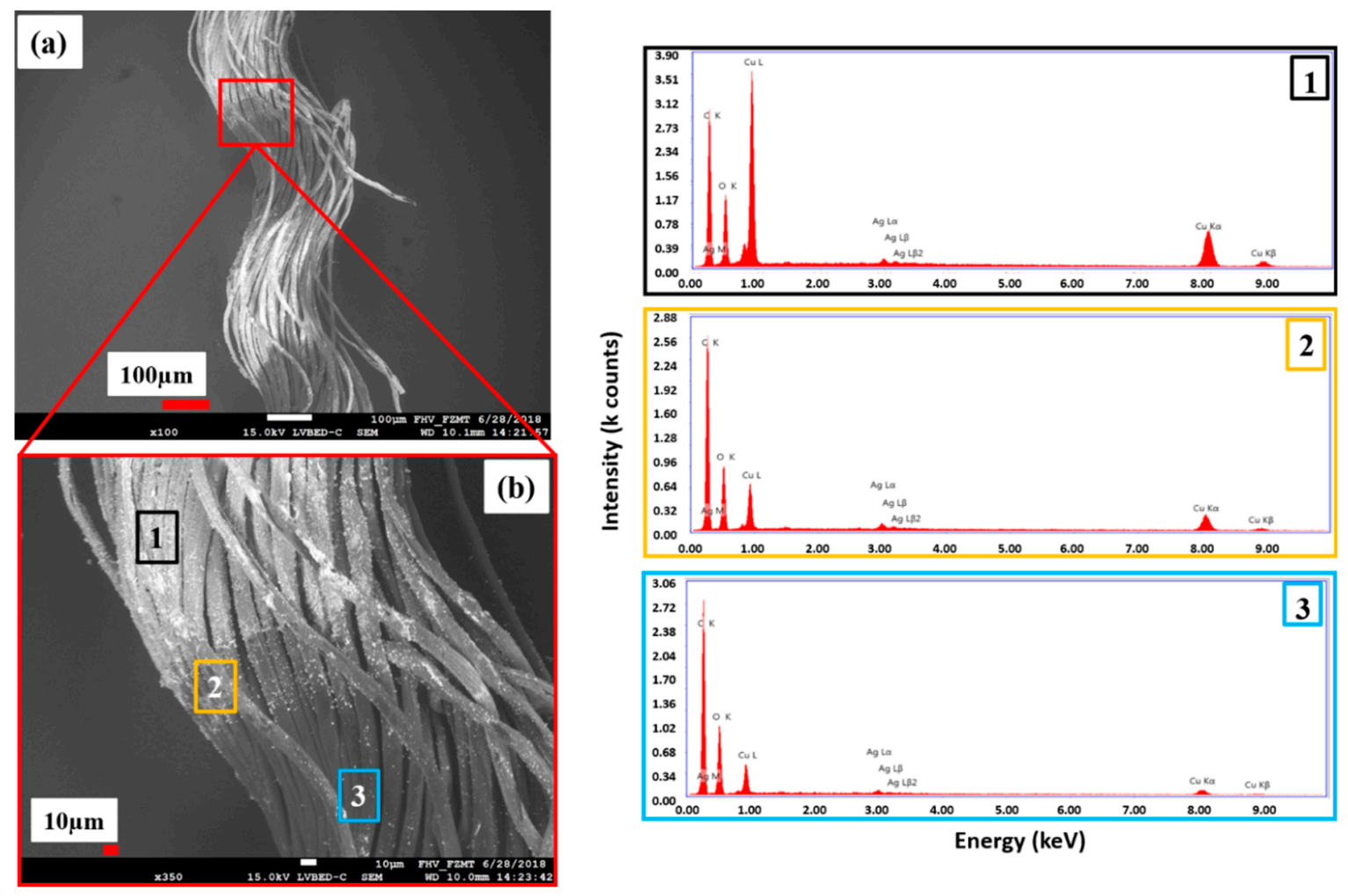

Figure 8. SEM/EDX investigations of the copper-coated CLY (CU1) yarn (a) show three different coating areas $(\mathbf{b})(1,2,3)$.

During the ECD, the copper species was differently distributed on the CLY fabric in an unstirred solution. Consequently, three different areas of copper species (areas 1,2,3) appeared on the CLY yarn (Figure $8 b$ ). This can be explained by different copper diffusion rates from the bulk to the surface and in the inner part of the CLY fabric. The $\mathrm{Cu}^{2+}$ ions diffused from solution and were reduced to $\mathrm{Cu}^{0}$ on the silver seed surface of the CLY leading to a copper coating. The diffusion of $\mathrm{Cu}^{2+}$ ions to the interior part of the CLY fabric was less efficient, which lead to no copper coating. According to the EDX spectra, copper peaks of low relative intensity were detected in area three (Figure 8 ) in comparison to area one and two. The relative intensity of copper peaks decreased from area one to area two and reached its lowest value in area three. Ag peaks from the Ag seeds were recorded at a low relative intensity comparing to the copper peaks while the $\mathrm{C}$ and $\mathrm{O}$ relative intensity peaks were similar in all EDX spectra.

\subsection{Mechanical Testing of the Copper-Coated Lyocell}

To design spatial copper conductor lines across the garment, one must take into account the critical places like knees and elbows. Such places are highly vulnerable with regard to bending and load during movement. Continuous flex cycles might cause permanent deformation of the garment, which could lead to a damaged copper layer and a loss of an electrical signal. The copper-coated CLY strip was subjected to continuous flex cycles around a cylinder of $15 \mathrm{~mm}$ radius in a flex test. During the flex cycles, the fabric did not come under tension. Therefore it is essential to investigate the sheet resistance of the copper layer after flex tests. Figure 9a depicts the results after different flex cycles of the copper-coated strip. 

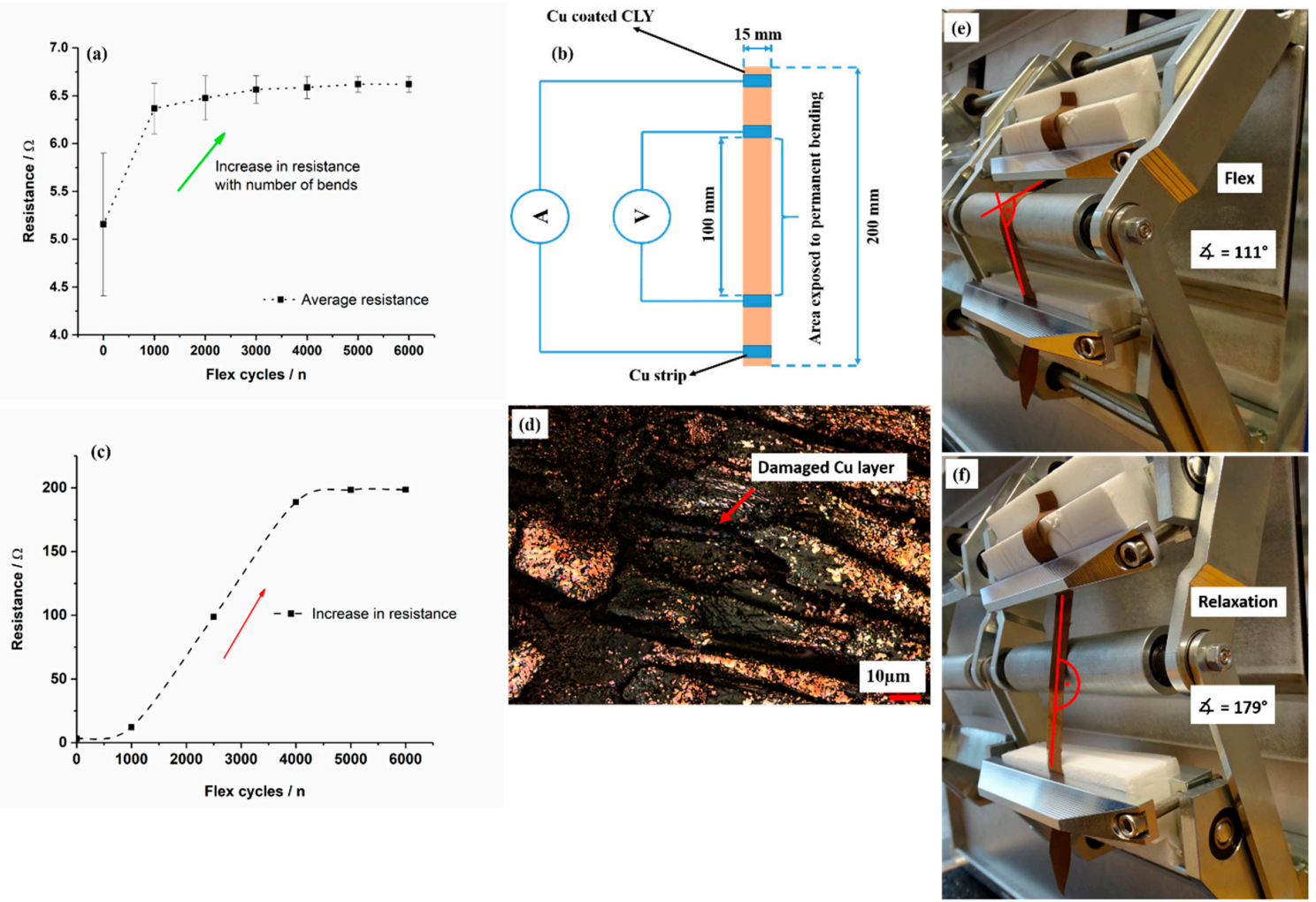

Figure 9. The change of resistance after flex tests (a) is measured with the four probe method (b). and with the two probe method (c). A damaged Cu layer of the CLY strip (CU 1) (d) is recorded with LSM after flex tests at different bending angles (e,f).

The resistance of the copper-coated CLY strip went up from $5.1 \Omega$ before flex cycles to $6.5 \Omega$ after 2000 flex cycles. It approached a plateau of $6.6 \Omega / 1500 \mathrm{~mm}^{2}$ from 4000 to 6000 flex cycles. The large error bars at zero flex cycles can be explained with the different local resistances of each copper-coated strip. After 1000 flex cycles, the topology indicated a damage of the copper coating, which increased the resistance (Figure 9d). The copper deposit broke apart after 1000 flex cycles by creating cracks in the coating. Due to the low change of resistance with extended flex cycles no further damage of the copper layer was observed. During flex cycles the angle of bending changed from $111^{\circ}$ to $179^{\circ}$ (Figure 9e,f) when the copper-coated strip was bended by a metallic cylinder. The resistance was measured after each 1000 flex cycle when the copper-coated CLY strip was placed on an isolating paper background without applying pressure during measurement (Figure 9b). In Figure 9 c, the resistance was measured with a two probe method during flex tests and approached a constant value of $200 \Omega$ after 6000 bending cycles. Abry et al. investigated a carbon fiber epoxy substrate, and obtained different electrical resistance [12]. In their post-buckling tests, the applied compressive load to carbon fiber differs to this work, in which a copper coating is investigated on non-conductive cellulose material.

\subsection{Cyclic Elongation of the Copper-Coated Lyocell}

In Figure 10, the resistance $(R)$ of the copper-coated CLY fabric changed as a function of cyclic elongation. The copper-coated CLY fabric was elongated and relaxed in a cycle, which was fixed between two jaws with an isolating rubber layer. The resistance change during elongation of $\mathrm{Cu}$-coated CLY strip of $28.5 \mathrm{~cm}^{2}$ was investigated with the four point method. During cyclic elongation, current was applied by the two outer $\mathrm{Cu}$ strips while measuring the voltage with two inner $\mathrm{Cu}$ strips (Figure 10c,d). 
(a)

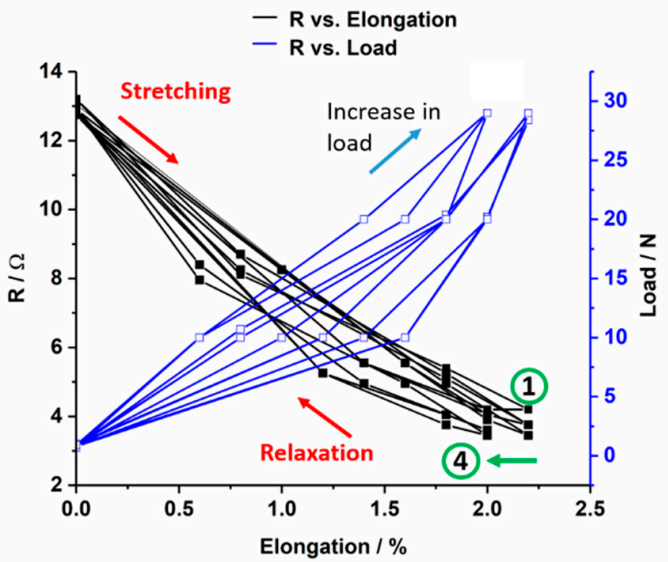

(b)

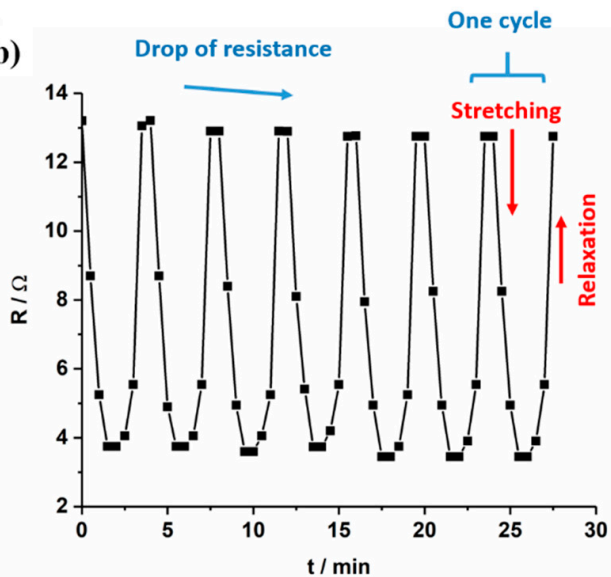

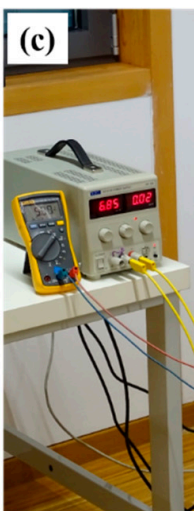

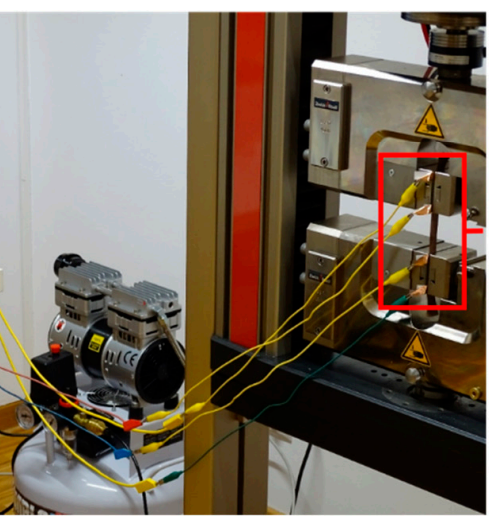

(d)

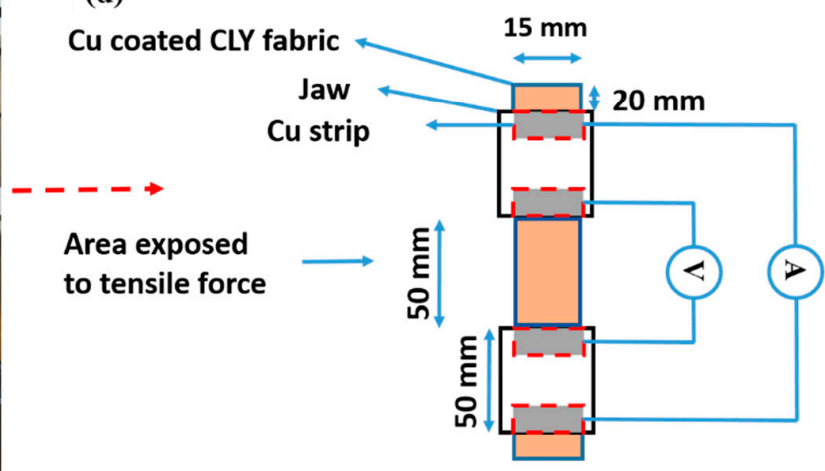

Figure 10. The change of resistance $R$ (Ohm) of the Cu-coated CLY fabric (CU 1) ( $d=15 \mathrm{~mm}, 1=50 \mathrm{~mm})$ and applied load are recorded as a function of elongation $(\mathbf{a})$ and time $(\mathbf{b})$. The detection of the resistance change was conducted with the four point technique $(\mathbf{c}, \mathbf{d})$.

The decrease and increase in resistance of the copper-coated CLY strip are investigated during cyclic elongation marked by black curves in Figure 10a. Blue curves show the elongation and relaxation of the copper-coated strip caused by an applied load. The resistance of the copper-coated CLY strip decreased during elongation and reached a stable value of $2 \%$ after 4 cycles as marked by a green arrow. Numbers one and four label those cycles. The contact between $\mathrm{Cu}$-coated yarns influenced the resistance of the CLY strip during elongation. During elongation, the Cu-coated CLY fibers are smashed by an applied load leading to an enlargement of the contact area and to a decrease in resistance. At relaxation, the resistance increased due to separation of the Cu-coated CLY yarns caused by a lower tensile force. Figure 10b depicts a steady decrease of the fabric's resistance with applied tensile force and an increase with relaxation. It is assumed that the applied tensile force squeezed the copper-coated yarns closer together by decreasing their distance. Thus, the copper-coated yarns were oriented in the direction of the applied tensile force, which caused a decrease in resistance during elongation. During relaxation, the resistance of the copper-coated cellulose increased upto $13.2 \Omega$, which can be explained through the small fabric's elongation of $2 \%$. The purpose for conducting the elongation test up to $2 \%$ was to investigate the suitability of the copper-coated cellulose fabric to be used in a respiration sensor. Since the movement of the human body during breathing does not have high strains, the respiratory sensor can be implemented in a garment to monitor breathing. The elongation of $2 \%$ is investigated on the inelastic cellulose material and is related its small thickness. After four cycles, the resistance went up and reached a constant value of $13 \Omega$ during further cycles. It is assumed that some copper fibers did not relax after four cycles. Long-time cyclic tests are predicated to show a constant resistance over time due to the smashed state of the copper-coated cellulose fibers during elongation. The resistance of the copper-coated cellulose fibers is expected to increase due to abrasion 
and damage of the copper coating during extended durability test, resulting in the sensitivity loss of the strain sensor. We expect the behavior of the Cu-coated cellulose similar to the PEDOT:PSS/PU sample as reported in the work of Ding et al. [37]. The results emphasize the potential of copper-coated CLY fabrics for strain sensors by monitoring textile deformation on a large scale (e.g., during breathing). Zhang et al. used stainless steel and carbon knitted fabrics during cyclic strain tests, whose work showed higher values of resistance during cyclic elongation [13]. In their experimental set-up, high strain and high resistances were related to a loosen sample structure comparing to a woven copper-coated cellulose in this work. Abu-Khalaf et al. produced stretchable circuits composed of PDMS (polydimethylsiloxane) and silver nanoparticle inks, which showed a resistance of $800 \Omega$ during stretching of $25 \%$ at $45^{\circ}$ [47]. In this work, a copper coating covered the surface of non-conductive cellulose.

\subsection{Copper-Coated Cellulose as Moisture Sensor}

In Figure 11, the resistance and the weight of a copper-coated CLY were investigated as a function of $\mathrm{RH}$. The change of the RH was measured between $20 \%$ and $80 \%$ in a climate chamber in air at $25^{\circ} \mathrm{C}$. The copper-coated fabric was preconditioned for $2 \mathrm{~h}$ in a climate chamber at $20 \% \mathrm{RH}$ and $25^{\circ} \mathrm{C}$. Subsequently, the change in $\mathrm{RH}$ was recorded stepwise at $30 \%, 50 \%, 70 \%$ and $80 \% \mathrm{RH}$. A period of acclimatization was needed between the steps for monitoring the fabric's weight. Using the mass balance for weight monitoring, allowed the time to be determined when the fabric's weight did not change leading to an equilibrium. After equilibrium, the resistance of the copper-coated fabric was measured with a four point technique and the RH was set to the next step. Its resistance and mass raised with the increase in $\mathrm{RH}$, which could be explained due to hygroscopic swelling of the cellulose yarns. An increase in the fabric's resistance might be explained due to the disruption of the current along the copper layer caused by hygroscopic expansion of the CLY fabric. During hygroscopic expansion of the CLY fabric, the copper coating was damaged between fibers and current can flow through a smaller copper coating area, which increased the resistance.

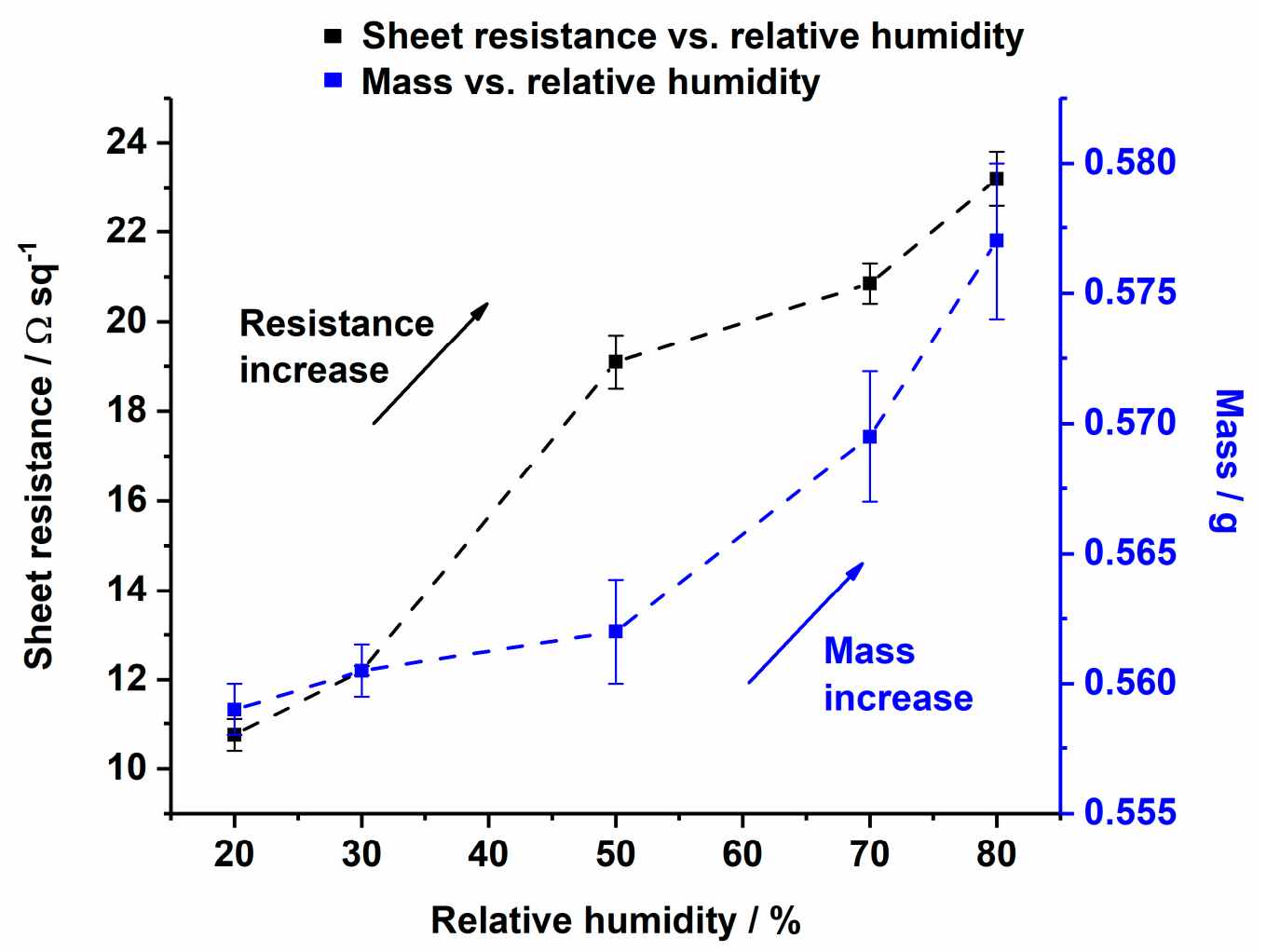

Figure 11. Change of sheet resistance (from $10.8 \Omega \mathrm{sq}^{-1}$ to $23 \Omega \mathrm{sq}^{-1}$ ) and mass change (from $0.55 \mathrm{~g}$ to $0.58 \mathrm{~g}$ ) of the Cu-coated CLY (CU 1) fabric as a function of relative humidity. 
Kramar et al. investigated the decrease in electrical resistance of cotton and viscose impregnated metal ion fabrics from Giga Ohm to the Mega Ohm magnitude [44]. Their material was not conductive due to the impregnation of metal ions, which differs to the conductive copper coating in this work.

\subsection{Durability in Water}

The resistance $(R)$ change of the copper-coated CLY strip was recorded as a function of time $(t)$ in air and in stirred $\mathrm{H}_{2} \mathrm{O}$ (DI) solution for $18 \mathrm{~h}$. It was measured with a two probe technique by using a Handheld LCR Meter. In air, it indicates a value of $35 \Omega$ in comparison to the resistance in water of $53 \Omega / 375 \mathrm{~mm}^{2}$ (Figure 12a). The aim of this work was to investigate the stability of copper-coated layer on CLY fabrics during repeated wetting/drying cycles. After first wetting (blue line) in $\mathrm{H}_{2} \mathrm{O}$ (DI), the electrical resistance was recorded over a time period of $18 \mathrm{~h}$ and raised from $53 \Omega$ to $85 \Omega$ comparing to the measurement in air. The copper-coated CLY fabric was dried for $14 \mathrm{~h}$ and immersed in to the second $\mathrm{H}_{2} \mathrm{O}$ (DI) solution for further $18 \mathrm{~h}$. Its resistance went up from $6 \mathrm{k} \Omega$ to $9.5 \mathrm{k} \Omega$, which might result from swelling and loosening of CLY fibers during wetting and drying. During the second measurement in air, the resistance of the copper-coated layer increased from $4 \mathrm{M} \Omega$ to $8 \mathrm{M} \Omega$. The repeated wetting and drying steps destroyed the copper layer on the CLY fabric due to the high resistance. Movement of non-coated fibers due to the inside swelling might damage the $\mathrm{Cu}$ layer on the surface. Oxidative corrosion might destroy the copper layer, which was not observed after the experiment due to the Figure 12b. Thus, the copper layer could be damaged by the mechanical deformation of the fabric, which led an increase in resistance. The Cu-coated CLY has a wavy structure, which makes monitoring of the resistance $(R)$ in water challenging due to the plain structure of the Cu strip electrodes (Figure 12b).

(a)
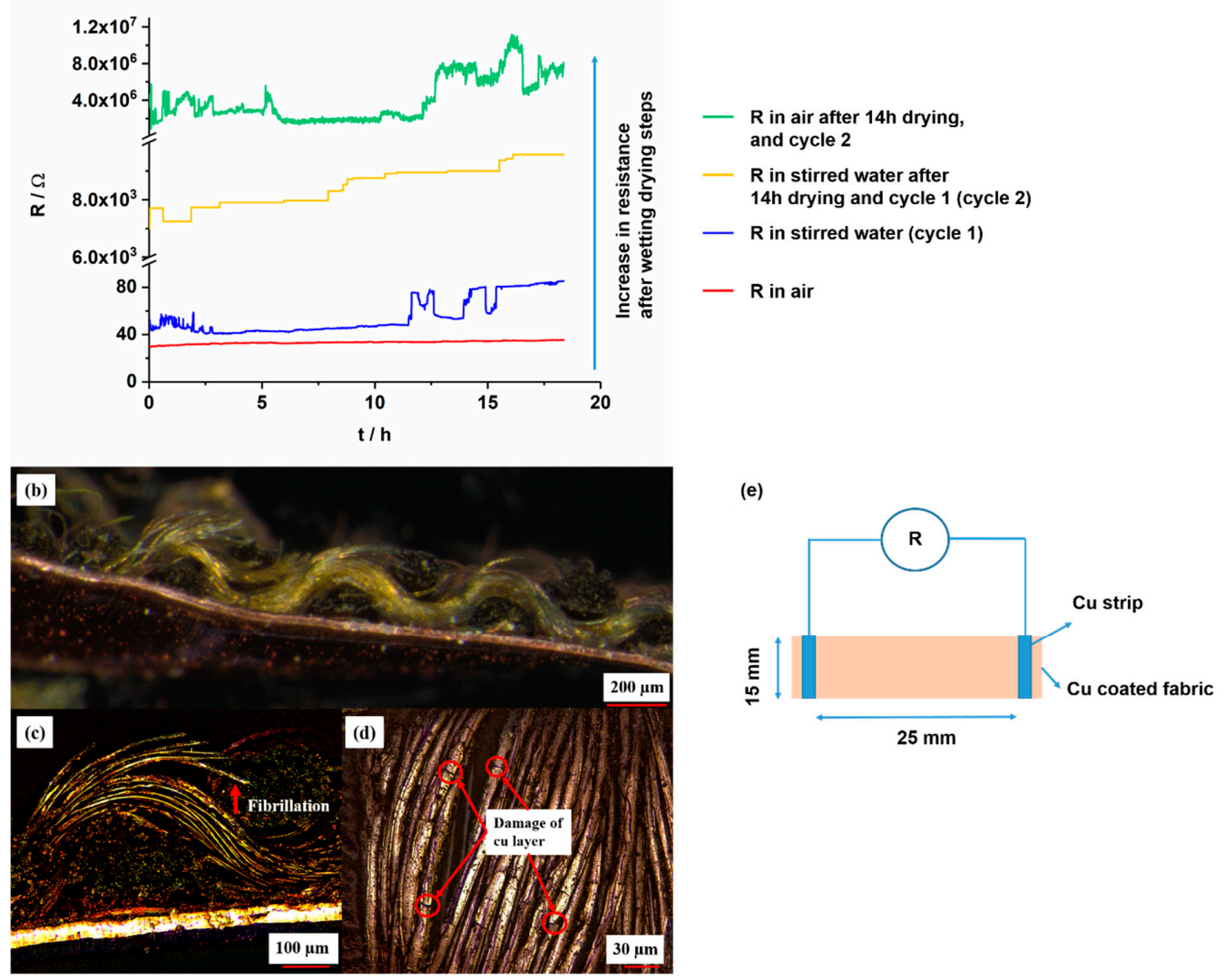

Figure 12. Resistance change of Cu-coated CLY (CU 1) fabrics ( $d=15 \mathrm{~mm}, 1=25 \mathrm{~mm}$ ) measured in air (red and green curves) and during stirring in water at $25^{\circ} \mathrm{C}$ at a stirring speed of $750 \mathrm{rpm}$ (blue and orange curves) (a). The figure shows a connection between Cu-coated CLY and Cu foil (b), the fibrillation of Cu-coated CLY fibers (c), the damaged copper coating (d) and the measuring procedure (e). 
Fibrillation of copper-coated CLY fibers from the yarn might lead to a decrease of the conductive contact area (Figure 12c). The decrease of the contact area between copper-coated fibers raised the electrical resistance during swelling. Swelling of cellulose fabric separated the copper-coated fibers in aqueous environment during which the CLY fabric was soaked with water. During drying in air, the water content evaporated from the copper-coated fabric, and the copper-coated fibers remain in a loosen state. Long term water treatment caused damage in the copper coating and increased its resistance from $38 \Omega$ to $16 \mathrm{M} \Omega$, which was observed after second drying step (Figure 12d). The copper-coated fabrics remained conductive after first wetting in water (DI) which can be explained through a good adhesion between the copper layer and the CLY substrate. Thus the cellulose material could be incorporated in smart textiles for an extended operation time during wet weather (e.g., raining). No peeling of the copper layer was observed during resistance measurement in water. As an alternative, a PES substrate can be used instead of cellulose to avoid swelling. The copper-coated CLY fabric was not a plane substrate, which was connected to the $\mathrm{Cu}$ strip through its wavy structure.

\subsection{FTIR Investigation}

In Figure 13, ATR-FTIR spectrum of uncoated and Cu-coated cellulose is shown, which confirms the chemical changes of the $\mathrm{Cu}$ coating at the textile surface. The $\mathrm{Cu}$-coated sample does not indicated characteristic cellulose peaks at $3442 \mathrm{~cm}^{-1}\left(\mathrm{O}(2) \mathrm{H} \mathrm{O}(6)\right.$ intramolecular hydrogen bond), $3340 \mathrm{~cm}^{-1}$ $\left(\mathrm{O}(3) \mathrm{H} \mathrm{O}(5)\right.$ intramolecular hydrogen bond), $2887 \mathrm{~cm}^{-1}$ (C-H stretch), $1018 \mathrm{~cm}^{-1}$ (C-O vibration at $\mathrm{C}(3) \mathrm{O}(3) \mathrm{H}), 991 \mathrm{~cm}^{-1}$ (C-O valence vibration at $\left.\mathrm{C}(6)\right)$ and $892 \mathrm{~cm}^{-1}$ (C-O-C valence vibration) [48].

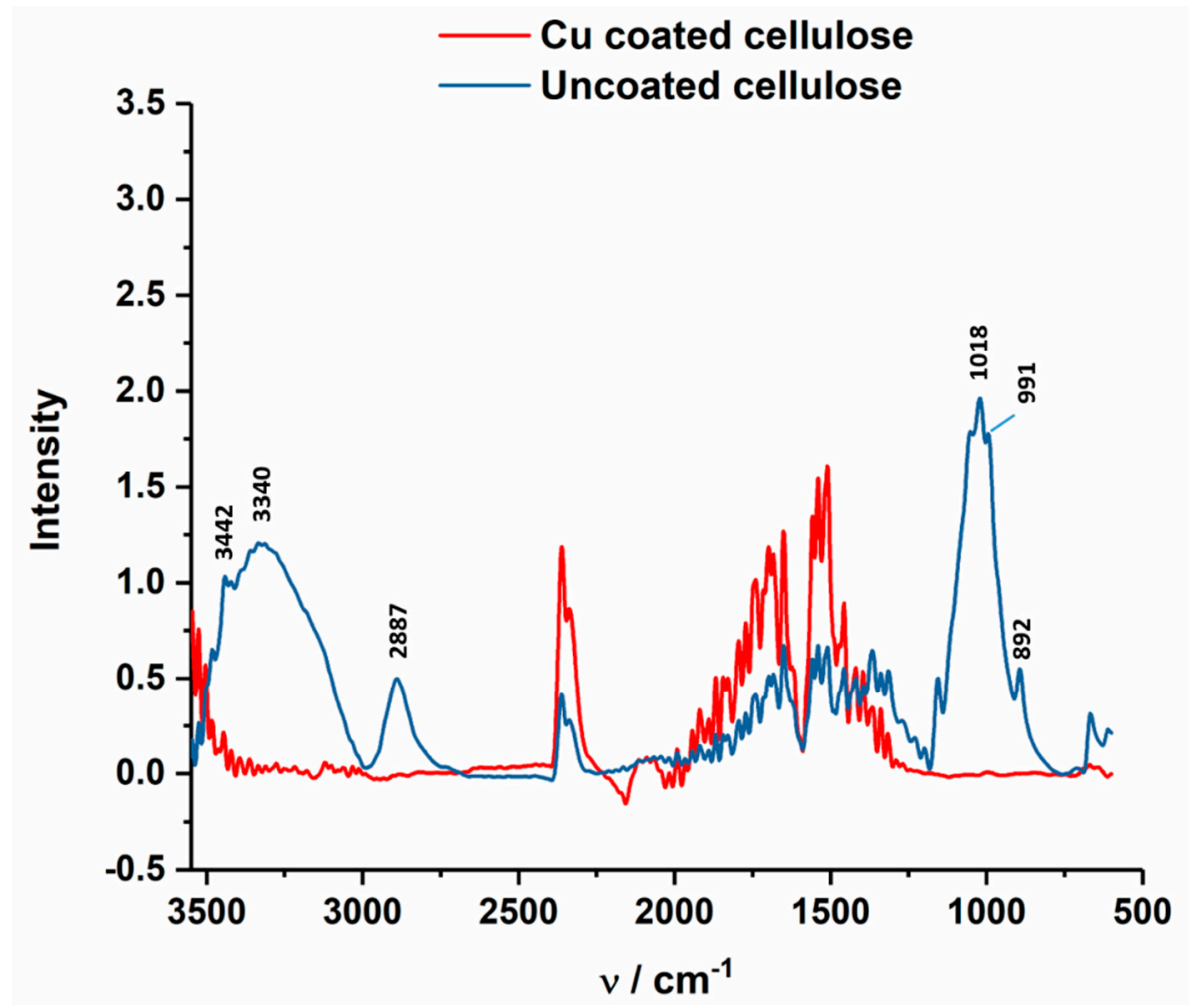

Figure 13. ATR-FTIR spectrum of Cu-coated cellulose (red) of the CU1 sample, which are compared to uncoated cellulose fabric (blue).

It is believed that the coating do not affect the crystallinity of the cellulose structure because of the $0.5 \mathrm{M} \mathrm{NaOH}$ concentration used during the electroless coating. In the work of Široký et al. molecular reorganization in the amorphous and quasi-crystalline areas is reported at 3.3 and $4.5 \mathrm{~mol} \mathrm{dm}{ }^{-3}$ of $\mathrm{NaOH}[48]$. 


\section{Conclusions}

This work showed that it was possible to slow down the chemical reaction of the electroless copper deposition at the silver seeded CLY surface by using different concentration of $\mathrm{Cu}^{2+}, \mathrm{CH}_{2} \mathrm{O}$, $\mathrm{C}_{4} \mathrm{H}_{5} \mathrm{KO}_{6}$, and $\mathrm{NaOH}$. High $\mathrm{Cu}^{2+}, \mathrm{C}_{4} \mathrm{H}_{5} \mathrm{KO}_{6}, \mathrm{NaOH}$, Tartrate, and $\mathrm{CH}_{2} \mathrm{O}$ concentrations led to a diffusion-controlled heterogeneous copper deposition and high homogeneous copper reaction in solution. The heterogeneous rate constant $k_{\text {het }}$ was large comparing to the homogeneous rate constant $k_{\text {hom }}$. Thus, the copper deposition on the cellulose surface did not increase further. The copper-coated CLY fabric was sensitive to mechanical deformations and humidity changes. Thus, it was able to transfer an electrical signal through the large surface area even at stretched and deformed condition by maintaining highly conductive due to the low resistance. The copper-coated CLY fabrics maintained conductivity after flex tests, cyclic tensile tests, during different $\mathrm{RH}$, and duringwetting for $18 \mathrm{~h}$ (cycle 1) (Figure 12) in water (DI). After 6000 bending cycles, the copper layer was partially damaged but the fabric kept its conductivity by indicating a resistance of $6.6 \Omega / 1500 \mathrm{~mm}^{2}$. During cyclic elongation, the resistance of the copper-coated CLY textile decreased. At elongated state, the distance between copper-coated yarns decreased with an increase in contact area. The resistance of the copper-coated textile reached a similar value of $13 \Omega / 750 \mathrm{~mm}^{2}$ due to small elongation of $2 \%$ after cyclic elongation tests. After cyclic elongation and flex tests, the copper layer was still attached to the CLY substrate, which reveals its strong adhesion to the textile. Continuous swelling and loosening of copper-coated CLY textile during wetting and drying increased the fabrics resistance. The increase in resistance to $16 \mathrm{M} \Omega / 375 \mathrm{~mm}^{2}$ can be related to damages in the Cu coating due to swelling and expansion of the CLY fabric. Fibrillation of the copper-coated CLY fabric was not observed according to LSM investigations.

Author Contributions: T.B. and T.P. defined the general concept of the study and revised the manuscript. T.W. designed experiments, revised and interpreted the data for cyclic elongation tests. B.C. designed experiments, revised and interpret the data for humidity tests. W.R. conducted the experiments, analyzed the Cu content with AAS and characterized the topology with LSM.

Funding: This research was funded by the CORNET framework in the project Ambitex - "Textile integrated sensors for monitoring of ambient parameters" (FFG 855282) and NanoStretch (FFG 865927).

Acknowledgments: The authors express thanks for providing woven CLY fabrics to Lenzing AG (Austria). Authors voice their gratitude to the Höhere Technische Bundeslehr- und Versuchsanstalt Dornbirn for the AAS accessibility. Additionally, authors thank Prof. Heinz Duelli from the Research Centre for Microtechnology of the FH Vorarlberg for the SEM images and EDX spectrum.

Conflicts of Interest: The authors declare no conflict of interest.

\section{References}

1. Hu, L.; Pasta, M.; La Mantia, F.; Cui, L.; Jeong, S.; Deshazer, H.D.; Choi, J.W.; Han, S.M.; Cui, Y. Stretchable, porous, and conductive energy textiles. Nano Lett. 2010, 10, 708-714. [CrossRef]

2. Ramuz, M.; Tee, B.C.K.; Tok, J.B.H.; Bao, Z. Transparent, optical, pressure-sensitive artificial skin for large-area stretchable electronics. Adv. Mater. 2012, 24, 3223-3227. [CrossRef]

3. Rogers, J.A.; Someya, T.; Huang, Y. (review)Materials and Mechanics for Stretchable Electronics. Science 2010, 327, 1603-1607. [CrossRef] [PubMed]

4. Wang, S.; Lu, A.; Zhang, L. Recent advances in regenerated cellulose materials. Prog. Polym. Sci. 2016, 53, 169-206. [CrossRef]

5. Singha, K. Importance of the Phase Diagram in Lyocell Fiber Spinning. Int. J. Mater. Eng. 2012, 2, 10-16. [CrossRef]

6. Someya, T.; Kato, Y.; Sekitani, T.; Iba, S.; Noguchi, Y.; Murase, Y.; Kawaguchi, H.; Sakurai, T. Conformable, flexible, large-area networks of pressure and thermal sensors with organic transistor active matrixes. Proc. Natl. Acad. Sci. USA 2005, 102, 12321-12325. [CrossRef] [PubMed]

7. Someya, T.; Sekitani, T.; Iba, S.; Kato, Y.; Kawaguchi, H.; Sakurai, T. A large-area, flexible pressure sensor matrix with organic field-effect transistors for artificial skin applications. Proc. Natl. Acad. Sci. USA 2004, 101, 9966-9970. [CrossRef] 
8. Huang, Y.; Hu, H.; Huang, Y.; Zhu, M.; Meng, W.; Liu, C.; Pei, Z.; Hao, C.; Wang, Z.; Zhi, C. From industrially weavable and knittable highly conductive yarns to large wearable energy storage textiles. ACS Nano 2015, 9, 4766-4775. [CrossRef] [PubMed]

9. Shur, M. Semiconductor Thin Films and Thin Film Devices for Electrotextiles. Int. J. High Speed Electron. Syst. 2002, 12, 317-390. [CrossRef]

10. Yang, L.; Zhou, W.; Jia, J.; Xiong, T.; Zhou, K.; Feng, C.; Zhou, J.; Tang, Z.; Chen, S. Nickel nanoparticles partially embedded into carbon fiber cloth via metal-mediated pitting process as flexible and efficient electrodes for hydrogen evolution reactions. Carbon N. Y. 2017, 122, 710-717. [CrossRef]

11. Matsuhisa, N.; Inoue, D.; Zalar, P.; Jin, H.; Matsuba, Y.; Itoh, A.; Yokota, T.; Hashizume, D.; Someya, T. Printable elastic conductors by in situ formation of silver nanoparticles from silver flakes. Nat. Mater. 2017, 16, 834-840. [CrossRef]

12. Abry, J.C.; Bochard, S.; Chateauminois, A.; Salvia, M.; Giraud, G. In situ detection of damage in CFRP laminates by electrical resistance measurements. Compos. Sci. Tech. 1999, 59, 925-935. [CrossRef]

13. Zhang, H.; Tao, X.; Yu, T.; Wang, S. Conductive knitted fabric as large-strain gauge under high temperature. Sensors Actuators, A Phys. 2006, 126, 129-140. [CrossRef]

14. Lin, Z.I.; Lou, C.W.; Pan, Y.J.; Hsieh, C.T.; Huang, C.H.; Huang, C.L.; Chen, Y.S.; Lin, J.H. Conductive fabrics made of polypropylene/multi-walled carbon nanotube coated polyester yarns: Mechanical properties and electromagnetic interference shielding effectiveness. Compos. Sci. Technol. 2017, 141, 74-82. [CrossRef]

15. Perumalraj, R. Electrical Surface Resistivity of Polyaniline Coated Woven Fabrics. J. Text. Sci. Eng. 2015, 5, 1-5. [CrossRef]

16. Hansen, T.S.; West, K.; Hassager, O.; Larsen, N.B. Highly stretchable and conductive polymer material made from poly(3,4-ethylenedioxythiophene) and polyurethane elastomers. Adv. Funct. Mater. 2007, 17, 3069-3073. [CrossRef]

17. Kageyama, K.; Yoshikawa, T.; Kato, H. Variation in Electrical Properties of Laminates with Woven Carbon Fabric and Ferroelectric or Piezoelectric Particulate Epoxy due to Tensile Loading. Mater. Trans. 2005, 46, 697-703. [CrossRef]

18. Yun, T.G.; Oh, M.; Hu, L.; Hyun, S.; Han, S.M. Enhancement of electrochemical performance of textile based supercapacitor using mechanical pre-straining. J. Power Sources 2013, 244, 783-791. [CrossRef]

19. Qu, M.; Nilsson, F.; Schubert, D. Effect of Filler Orientation on the Electrical Conductivity of Carbon Fiber/PMMA Composites. Fibers 2018, 6, 3. [CrossRef]

20. Won, Y.; Kim, A.; Yang, W.; Jeong, S.; Moon, J. A highly stretchable, helical copper nanowire conductor exhibiting a stretchability of 700. NPG Asia Mater. 2014, 6, e132. [CrossRef]

21. Ali, A.; Baheti, V.; Militky, J.; Khan, Z.; Tunakova, V.; Naeem, S. Copper coated multifunctional cotton fabrics. J. Ind. Text. 2017, 48, 448-464. [CrossRef]

22. Nishio, Y.; Todoroki, A.; Mizutani, Y.; Suzuki, Y. Piezoresistive effect of plain-weave CFRP fabric subjected to cyclic loading. Adv. Compos. Mater. 2017, 26, 229-243. [CrossRef]

23. De Baere, I.; Van Paepegem, W.; Degrieck, J. Electrical resistance measurement for in situ monitoring of fatigue of carbon fabric composites. Int. J. Fatigue 2010, 32, 197-207. [CrossRef]

24. Cui, H.; Suganuma, K.; Uchida, H. Highly stretchable, electrically conductive textiles fabricated from silver nanowires and cupro fabrics using a simple dipping - drying method. Nano Res. 2015, 8, 1604-1614. [CrossRef]

25. Wang, D.; Zhang, Y.; Lu, X.; Ma, Z.; Xie, C.; Zheng, Z. Chemical formation of soft metal electrodes for flexible and wearable electronics. Chem. Soc. Rev. 2018, 47, 4611-4641. [CrossRef] [PubMed]

26. Tao, X. Handbook of Smart Textiles, 1st ed.; Springer: Hong Kong, 2015; ISBN 9789814451451.

27. Dias, T. Electronic Textiles: Smart Fabrics and Wearable Technology, 1st ed.; Dias, T., Ed.; Woodhead: Oxford, UK, 2015; ISBN 9780081002018.

28. Jia, J.; Xu, C.; Pan, S.; Xia, S.; Wei, P.; Noh, H.Y.; Zhang, P.; Jiang, X. Conductive Thread-Based Textile Sensor for Continuous Perspiration Level Monitoring. Sensors 2018, 18, 3775. [CrossRef] [PubMed]

29. Bajgar, V.; Penhaker, M.; Martinková, L.; Pavlovic, A.; Bober, P.; Trchová, M.; Stejskal, J. Cotton Fabric Coated with Conducting Polymers and its Application in Monitoring of Carnivorous Plant Response. Sensors 2016, 16, 498. [CrossRef] [PubMed]

30. Zieba, J.; Frydrysiak, M. Textronics - Electrical and electronic textiles. Sensors for breathing frequency measurement. Fibres Text. East. Eur. 2006, 14, 43-48. 
31. Ehrmann, A.; Heimlich, F.; Brücken, A.; Weber, M.; Haug, R. Suitability of knitted fabrics as elongation sensors subject to structure, stitch dimension and elongation direction. Text. Res. J. 2014, 84, 2006-2012. [CrossRef]

32. Li, L.; Liu, S.; Ding, F.; Hua, T.; au, W.M.; Wong, K.S. Electromechanical analysis of length-related resistance and contact resistance of conductive knitted fabrics. Text. Res. J. 2012, 82, 2062-2070. [CrossRef]

33. Kongahage, D.; Foroughi, J. Actuator Materials: Review on Recent Advances and Future Outlook for Smart Textiles. Fibers 2019, 7, 21. [CrossRef]

34. Atalay, O.; Richard Kennon, W.; Dawood Husain, M. Textile-based weft knitted strain sensors: Effect of fabric parameters on sensor properties. Sensors (Switzerland) 2013, 13, 11114-11127. [CrossRef]

35. Atalay, O.; Kennon, W. Knitted Strain Sensors: Impact of Design Parameters on Sensing Properties. Sensors 2014, 14, 4712-4730. [CrossRef]

36. Hu, J.; Zhou, S.; Shi, J.; Zhang, H.; Zhu, F.; Yang, X. Determinants of electrical resistance change of in situ PPy-polymerized stretch plain woven fabric under uniaxial tensile strain. J. Text. Inst. 2017, 108, 1545-1551. [CrossRef]

37. Ding, Y.; Xu, W.; Wang, W.; Fong, H.; Zhu, Z. Scalable and Facile Preparation of Highly Stretchable Electrospun PEDOT:PSS@PU Fibrous Nonwovens toward Wearable Conductive Textile Applications. ACS Appl. Mater. Interfaces 2017, 9, 30014-30023. [CrossRef] [PubMed]

38. Mahmood, H.; Dorigato, A.; Pegoretti, A. Temperature Dependent Strain/Damage Monitoring of Glass/Epoxy Composites with Graphene as a Piezoresistive Interphase. Fibers 2019, 7, 17. [CrossRef]

39. Ding, Y.; Xu, T.; Onyilagha, O.; Fong, H.; Zhu, Z. Recent advances in flexible and wearable pressure sensors based on piezoresistive 3D monolithic conductive sponges. ACS Appl. Mater. Interfaces 2019, 11, 6685-6704. [CrossRef]

40. Baima, M.; Andrew, T. Fluoropolymer-Wrapped Conductive Threads for Textile Touch Sensors Operating via the Triboelectric Effect. Fibers 2018, 6, 41. [CrossRef]

41. Ebrahimi, I.; Gashti, M.P. Chemically reduced versus photo-reduced clay-Ag-polypyrrole ternary nanocomposites: Comparing thermal, optical, electrical and electromagnetic shielding properties. Mater. Res. Bull. 2016, 83, 96-107. [CrossRef]

42. Široká, B.; Manian, A.P.; Noisternig, M.F.; Henniges, U.; Kostic, M.; Potthast, A.; Griesser, U.J.; Bechtold, T. Wash-dry cycle induced changes in low-ordered parts of regenerated cellulosic fibers. J. Appl. Polym. Sci. 2012, 126, E396-E407. [CrossRef]

43. Jaturapiree, A.; Ehrhardt, A.; Groner, S.; Öztürk, H.B.; Siroka, B.; Bechtold, T. Treatment in swelling solutions modifying cellulose fiber reactivity - Part 1: Accessibility and sorption. Macromol. Symp. 2008, 262, 39-49. [CrossRef]

44. Kramar, A.D.; Asanović, K.A.; Obradović, B.M.; Kuraica, M.M.; Kostić, M.M. Electrical Resistivity of Plasma Treated Viscose and Cotton Fabrics with Incorporated Metal Ions. Fibers Polym. 2018, 19, 571-579. [CrossRef]

45. Shim, B.S.; Chen, W.; Doty, C.; Xu, C.; Kotov, N.A. Smart electronic yarns and wearable fabrics for human biomonitoring made by carbon nanotube coating with polyelectrolytes. Nano Lett. 2008, 8, 4151-4157. [CrossRef] [PubMed]

46. Root, W.; Aguiló-Aguayo, N.; Pham, T.; Bechtold, T. Conductive layers through electroless deposition of copper on woven cellulose lyocell fabrics. Surf. Coatings Technol. 2018, 348, 13-21. [CrossRef]

47. Abu-khalaf, J.; Saraireh, R.; Eisa, S.; Al-Halhouli, A. Experimental Characterization of Inkjet-Printed Stretchable Circuits forWearable Sensor Applications. Sensors 2018, 18, 3476. [CrossRef]

48. Široký, J.; Blackburn, R.S.; Bechtold, T.; Taylor, J.; White, P. Attenuated total reflectance Fourier-transform Infrared spectroscopy analysis of crystallinity changes in lyocell following continuous treatment with sodium hydroxide. Cellulose 2010, 17, 103-115. [CrossRef]

(C) 2019 by the authors. Licensee MDPI, Basel, Switzerland. This article is an open access article distributed under the terms and conditions of the Creative Commons Attribution (CC BY) license (http://creativecommons.org/licenses/by/4.0/). 